\title{
Binary nucleation in acid-water systems. I. Methanesulfonic acid-water
}

\author{
B. E. Wyslouzil, J. H. Seinfeld, and R. C. Flagan \\ Department of Chemical Engineering, California Institute of Technology, Pasadena, California 91125 \\ K. Okuyama \\ Department of Chemical Engineering, Hiroshima University, Saijo-cho, Higashi-Hiroshima, Japan
}

(Received 22 October 1990; accepted 29 January 1991)

\begin{abstract}
Experimental measurements of binary nucleation between methanesulfonic acid and water vapor were carried out for relative acidities $(\mathrm{Ra}), 0.05<\mathrm{Ra}<0.65$, and relative humidities $(\mathrm{Rh}), 0.06<\mathrm{Rh}<0.65$, using a continuous flow mixing-type device. The number concentration of particles leaving the nucleation and growth tube was measured as a function of the initial relative humidity and the relative acidity in the temperature range from 20 to $30^{\circ} \mathrm{C}$. Particle size distributions were also measured and found to vary with the amount of water and acid present. The system was simulated to predict the total number of particles and the total mass of acid in the aerosol phase using a simple integral model and classical binary nucleation theory allowing for the formation of acid-water hydrates in the gas phase. At low particle concentrations, condensation rates did not significantly change the saturation levels and the nucleation rates were estimated from the total number concentration data as functions of $\mathrm{Ra}, \mathrm{Rh}$, and temperature. The values of experimental and theoretical nucleation rates differed significantly, with $J_{\text {expt }} / J_{\text {theor }}$ changing as a function of temperature from $10^{-8}$ to $10^{-4}$ as temperature varied from 20 to $30^{\circ} \mathrm{C}$. This work represents the first systematic experimental study of the temperature dependence of binary nucleation.
\end{abstract}

\section{INTRODUCTION}

Significant particle formation by heteromolecular, homogeneous nucleation between an acid gas and water vapor was first predicted for sulfuric acid and water by Doyle ${ }^{1}$ using the binary nucleation theory developed by Reiss. ${ }^{2}$ Since then, only three acid--water systems have been studied experimentally; these are sulfuric acid $\left(\mathrm{H}_{2} \mathrm{SO}_{4}\right)$-water, nitric acid $\left(\mathrm{HNO}_{3}\right)$-water, and methanesulfonic acid $\left(\mathrm{CH}_{3} \mathrm{HSO}_{4}\right)$-water.

Reiss et al. ${ }^{3}$ had limited success using an expansion chamber to study nucleation in the sulfuric acid and water systems, encountering problems related to corrosion and the low vapor pressure of $\mathrm{H}_{2} \mathrm{SO}_{4}$. The high expansion ratios required in their experiments produced low final temperatures $\left(-28.5^{\circ} \mathrm{C}\right.$ to $\left.-51.7^{\circ} \mathrm{C}\right)$ which makes comparison with theory difficult because the measured thermodynamic data exist only at much higher temperatures. On further analysis, Shelling and Reiss ${ }^{4}$ concluded that expansion chambers or nozzles were not well suited for measuring the critical supersaturation ratios in $\mathrm{H}_{2} \mathrm{SO}_{4}$-water vapor mixtures.

Boulaud et al..$^{5}$ mixed varying amounts of $\mathrm{SO}_{3}$ and water vapor in a $200 \ell$ vessel and measured the resulting particle concentration as a function of time, from which they estimated the nucleation rates. The change in nucleation rate, $J$, with respect to time, due to changes in the saturation level of the acid in the vessel, was not considered and so their data represent at best an estimate of $J_{\text {avg }}$ for the first $150 \mathrm{~s}$ of the experiments.

Mirabel and Clavelin ${ }^{6}$ used an upward thermal diffusion chamber to measure the onset of nucleation (nucleation rate, $J=2-3 \mathrm{~cm}^{-3} \mathrm{~s}^{-1}$ ) in both the nitric acid-water and sulfuric acid-water systems. They were able to investigate the nitric acid-water system for $0<\mathrm{Rh}<3$ and at two temperatures, 5 and $25^{\circ} \mathrm{C}$, but they did not comment on the effect of temperature on the critical saturation ratios. In the case of sulfuric acid-water they investigated only $T=25^{\circ} \mathrm{C}$, and values of $\mathrm{Rh}<1$ were not possible because of the low vapor pressure of $\mathrm{H}_{2} \mathrm{SO}_{4}$. Nucleation rate measurements represent a more sensitive test of the theory than simple measurements of the onset of nucleation, and thermal diffusion chambers have only recently been used for this purpose in the case of single component nucleation. ${ }^{7}$

Nucleation in the methanesulfonic acid-water system was first studied experimentally by Kreidenweis et al. ${ }^{8}$ for $T=25^{\circ} \mathrm{C}$ and $\mathrm{Ra}, \mathrm{Rh}<1.0$. Methanesulfonic acid (MSA) is a naturally occurring oxidation product of biogenically produced dimethyl sulfide, and recent interest has focused on estimating the contribution of this material to the formation of nonsea-salt aerosols over the remote pacific, its potential as a source of cloud condensation nuclei, and its role in the overall global sulfur budget. ${ }^{9.10}$ Measured nucleation rates for this system are therefore of interest, both in their own right, as well as for comparison with those of sulfuric acid which is also considered a major source of atmospheric aerosol particles. This comparison will be made in paper II where the data from $\mathrm{H}_{2} \mathrm{SO}_{4}$-water nucleation experiments are presented.

The MSA-water nucleation measurements of Kreidenweis et al. ${ }^{8}$ employed a continuous-flow mixing-type device first applied to binary nucleation studies by Okuyama et $a l{ }^{11}$ In this device particle-free gas streams saturated with the desired acid and water vapor are rapidly mixed at known temperatures and pressures to create well characterized initial conditions. The mixed stream is then allowed to nucleate, and the particles grow while flowing through an isothermal flow tube. The number concentration of particles 
produced is measured at the outlet of the nucleation and growth tube using a high resolution particle counter and provides a sensitive measure of the binary nucleation rate. Although the continuous flow experimental approach has some drawbacks, for instance at very high nucleation rates mixing and nucleation may be occurring over comparable time scales, it appears to be the simplest available method for generating consistent and reliable nucleation rate data in acid-water systems under controlled, isothermal, and subsaturated conditions.

The present work expands on that of Kreidenweis et $a l .{ }^{8}$ incorporating several changes to the apparatus that allow for better control of the experimental flows and temperatures. These modifications are reflected in the improved repeatability of the results which makes it possible to distinguish real variations in nucleation rates, due to changes in such variables as temperature, from problems in experimental repeatability. In addition, the effects of temperature on the nucleation process are systematically investigated and particle size distributions are measured to further elucidate the competition between nucleation and condensation in such systems. The experimental data are then evaluated against classical binary nucleation theory.

\section{THE CONTINUOUS FLOW MIXING DEVICE AND EXPERIMENTAL PROCEDURES}

Figure 1 shows a schematic of the experimental apparatus used in the nucleation experiments. The equipment is similar to that used by Kreidenweis et al. ${ }^{8}$ but it has been modified in several key areas. In particular, improvements have been made in flow control and measurement, the design of the acid bubbler has been changed to reduce pressure buildup during experiments and to facilitate cleaning, and the use of a single large water bath gives better temperature control.

Extra-dry bottled air is used as the carrier gas in the experiments. After passing the air through a conditioning column containing silica gel, a $10 \AA$ molecular sieve, and a high capacity Teflon filter with a $0.2 \mu \mathrm{m}$ pore size, the pressure is reduced from $275 \mathrm{kPa}$ to about $100 \mathrm{kPa}$. The flow is then split into the three streams required in the experiments; a stream of air to be saturated with water $F_{h}$, a stream to be saturated with acid $F_{a}$, and a stream of air for dilution $F_{d}$. The flowrates of these streams are measured using flowmeters consisting of glass capillary tubes and 0-10 Torr differential pressure transducers. The flows are controlled by needle valves placed at the downstream end of the flow capillaries. Thus the pressure in the capillary tubes is maintained and is relatively insensitive to downstream pressure fluctuations. The calibrated range of each flow capillary is 20 $1000 \mathrm{~cm}^{3} \mathrm{~min}^{-1}$. All of the lines used for air transfer are dehydrated copper, Teflon, or polyflow tubing. All of the surfaces in contact with acid or acid gas are glass, Teflon, or Viton. Swagelok ${ }^{\mathrm{TM}}$ fitting are used throughout the apparatus.

The air is saturated with water by bubbling the air stream through a series of two water bubblers containing ultrapure water. The first bubbler is at room temperature while the second bubbler is fully immersed in the large water bath. Calibrated thermistors are used to measure temperatures throughout the system, and the temperature of the final humidification stage is measured by a thermistor $(T 1)$ encased in a glass tube submerged in the liquid. The pressure

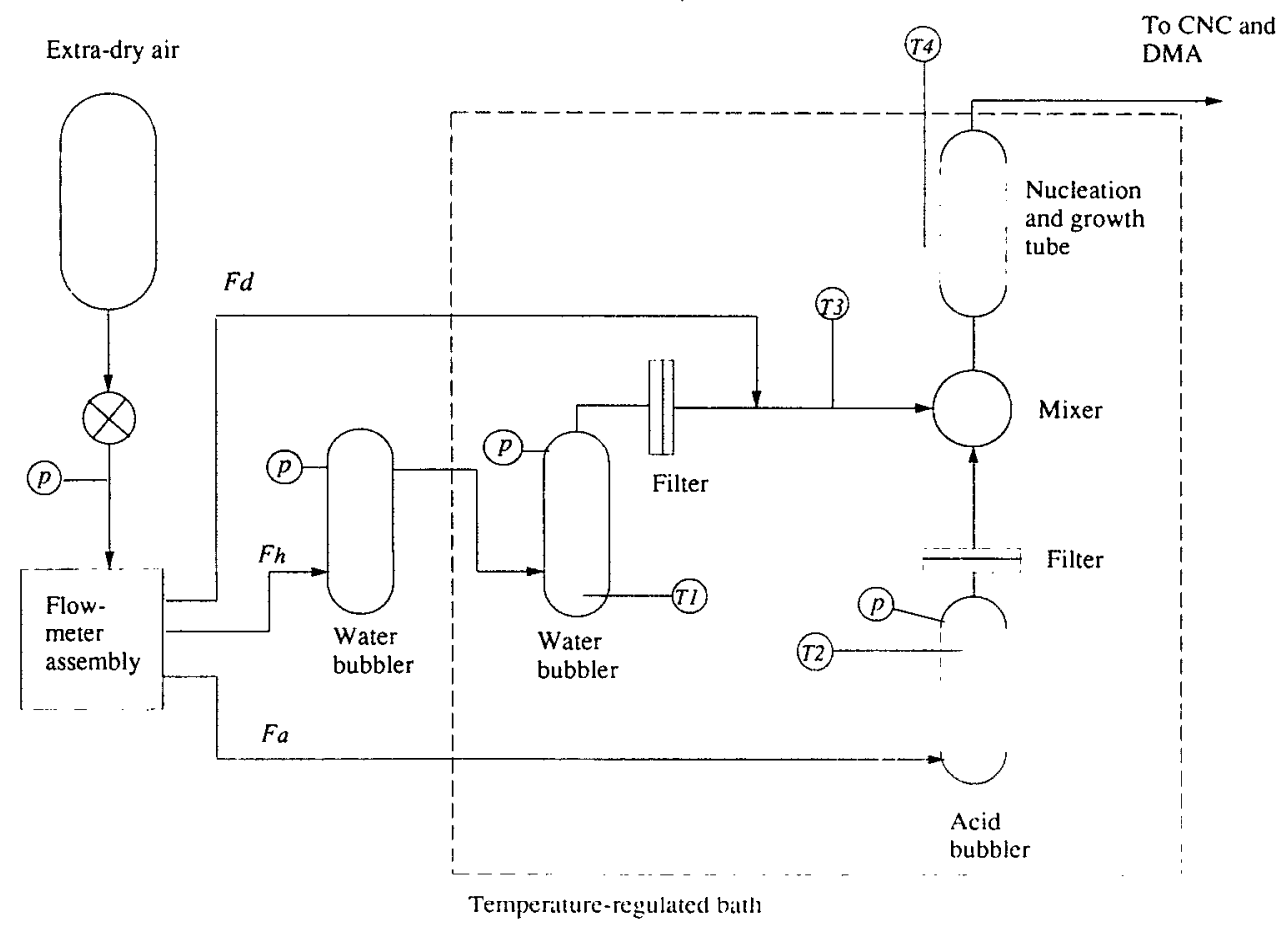

FIG. 1. Schematic of the experimental equipment. 
inside the water bubbler is measured at a pressure tap located near the top of the bubbler. At the exit of the bubbler a filter assembly containing two $0.2 \mu \mathrm{m}$ pore size Teflon filters, eliminates the entrained liquid water droplets.

Dry dilution air is added to the humid stream at the tee between the water bubbler and the mixer. This stream allows the relative acidity and relative humidity to be varied while still maintaining a constant total flow rate through the nucleation and growth tube. The temperature of the mixed humid stream is measured just before it enters the mixer ( $T 3$, to confirm that the temperature of this stream is the same as the bath and the acid stream temperatures.

The air to be saturated with acid enters the bottom of the acid bubbler and bubbles through a pool of acid supported on a $60 \mathrm{~mm}$ wide fine frit. A thermistor $(T 2)$ enclosed in a glass tube measures the temperature of the acidified air near the top of the bubbler. The pressure inside the bubbler is measured at a nearby pressure tap. A filter assembly containing two $41 \mathrm{~mm}$ diameter Teflon filters with pore size of 0.2 $\mu \mathrm{m}$, removes entrained acid particles without imposing a large pressure drop between the acid bubbler and the mixer.

Figure 2 illustrates the overall acid bubbler, mixer, and nucleation and growth tube assembly. The mixer is machined entirely of Tefion and is located directly above the acid bubbler. The acidic air enters the central chamber from the bottom, while the humid air is injected through eight 0.5 $\mathrm{mm}$ diameter holes surrounding the chamber. The distance from the top of the acid filters to the center of the mixing

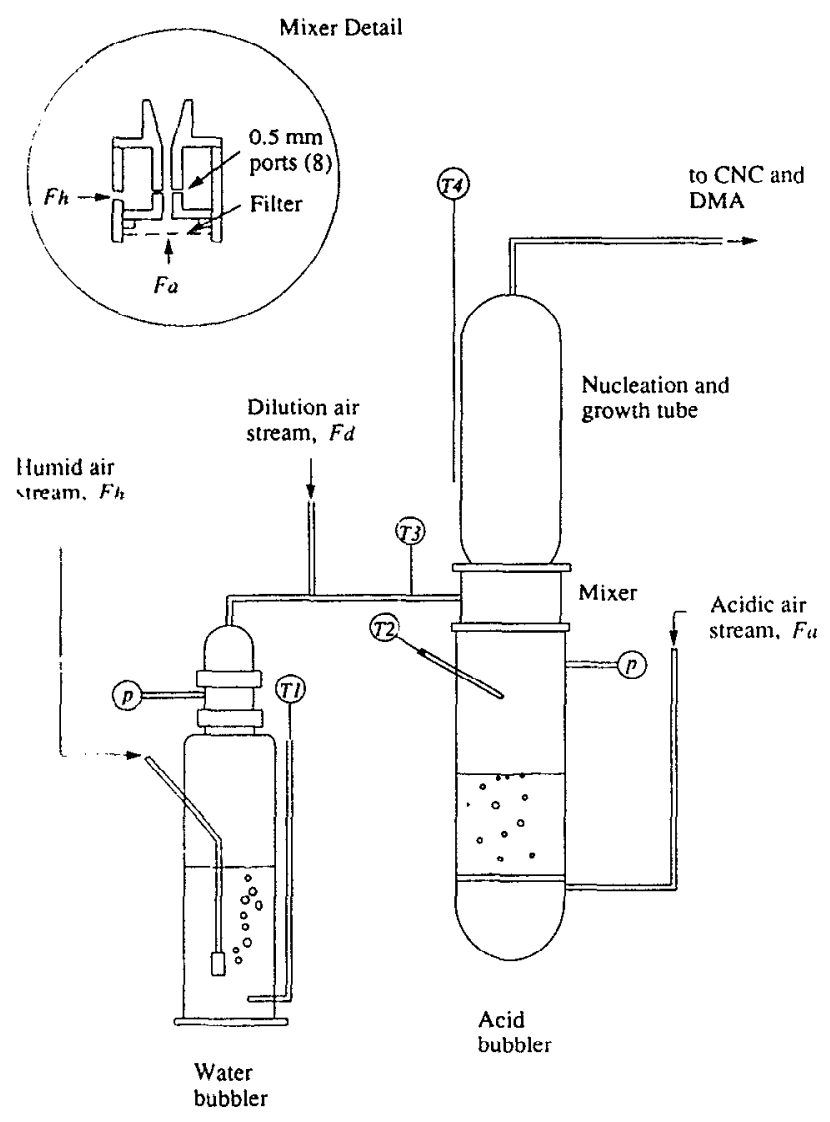

FIG. 2. Details of the continuous flow mixing type nucleation system. chamber is less than $1.5 \mathrm{~cm}$ to minimize vapor loss between the position where equilibrium of the acid is assumed and where the two vapor streams combine. The rapid mixing promoted by the geometry of the mixer gives rise to the desired initial conditions of relative humidity and relative acidity. Above the mixer, a $51 \mathrm{~mm}$ diameter glass tube with a volume of $280 \mathrm{~cm}^{3}$, provides time for the nucleation and growth of the particles. A thermistor in the water bath just outside the tube and about halfway down $(T 4)$, measures the temperature at which nucleation occurs.

The flow from the nucleation and growth tube exits to a $10 \mathrm{~mm}\left(3 / 8^{\prime \prime}\right)$ glass tube. The level of the water in the temperature-regulated bath is maintained at this height. A $6 \mathrm{~mm}$ $\left(1 / 4^{\prime \prime}\right)$ Teflon tube leads from the tube exit, through the wall of the bath to a TSI model 3020 condensation nucleus counter (CNC). The CNC draws $300 \mathrm{~cm}^{3} \mathrm{~min}^{-1}$ of the flow and the excess flow is vented.

Particles size distributions are measured using the scanning electrical mobility spectrometer (SEMS) ${ }^{12}$ when the particle concentration is high enough $\left(\gtrsim 5 \times 10^{3} \mathrm{~cm}^{-3}\right)$. This instrument rapidly scans the entire particle size distribution by exponentially ramping the collector rod voltage of a TSI model 3071 differential mobility analyzer (DMA) with the transmitted particles being counted by a TSI model 3076 CNC. An IBM AT computer controls the collector rod voltage of the DMA, counts the particles detected by the $\mathrm{CNC}$ in successive time intervals, and displays the calculated size distribution. Particle size distributions were taken at two to six different conditions during an experiment and ten scans were taken at each condition to assure a representative distribution. The $3076 \mathrm{CNC}$ requires a flow of $\sim 1.6 \mathrm{\ell min}^{-1}$ and experiments were generally run at $1.0 \ell \mathrm{min}^{-1}$ total flow; therefore clean filtered room air is drawn into the line between the classifier and the CNC to make up the difference in flows. The use of lab air at this point will not change the number of particles measured by the CNC because the experiments are all run at low relative humidity.

The expcriments all used a total flow rate of $1.0 \ell \mathrm{min}^{-1}$ (measured at STP) to maintain a constant residence time of about $18 \mathrm{~s}$ in the nucleation and growth tube. In each experiment a value of relative acidity or relative humidity was selected and then the value of the other variable was changed to obtain conditions where total number concentrations ranged from near zero to as high as possible. Generally it was possible to observe a change in total particle concentration of five to seven orders of magnitude. Experiments were started cither at a high or low number concentration and the relative saturation level of interest was changed in increments of 0.01 to 0.05 . The total number of particles was recorded when the new conditions had stabilized, 2 to 5 min after selecting a new condition. This time corresponded to 7 to 18 times the residence time of the nucleation and growth tube. Total number concentration measurements were then recorded manually for several minutes with 8 to 30 values recorded at each setting from which a mean value was subsequently calculated. Before taking any measurements, the cquipment was run for more than $10 \mathrm{~h}$ after the addition of acid to assure stable operating conditions.

Figure 3 shows a schematic of the type of data curves 


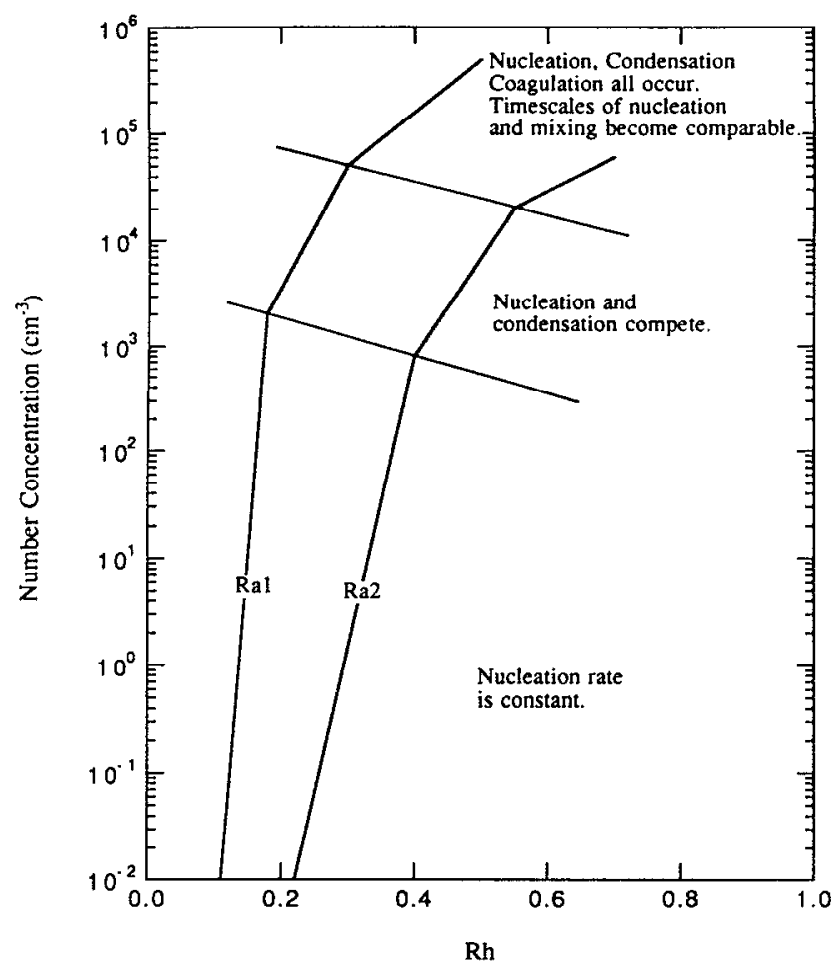

FIG. 3. Typical operating regimes for the continuous flow mixing type nucleation system.

generated, and indicates the different operating regimes that exist during a complete nucleation experiment. The fundamental principle of the continuous flow nucleation experiments is that at small observed number concentration condensation rates are sufficiently low that the acid saturation level, and hence the nucleation rate, remains constant from the time of mixing until the particles are counted. Thus in this regime the nucleation rate may be calculated by dividing the observed number concentration by the length of time over which nucleation occurs. Because of the low vapor pressure of the acid with respect to that of water, the saturation level of water will be constant even at high nucleation rates. The initial stccp increase in the observed number concentrations with saturation level corresponds to the constant nucleation rate regime.

As the saturation level of one component and the observed number concentration increase further, condensation begins to compete effectively with nucleation and reduces the acid saturation so that nucleation is rapidly quenched after the initial mixing. Because the length of time during which constant nucleation is occurring cannot be easily determined, these data points cannot be used to calculate nucleation rates. They do however provide additional test points with which to compare the results from an integral model that accounts for both nucleation and condensation. This regime is analogous to that described by Hung et al. ${ }^{7}$ when measuring nucleation rates using an upward thermal diffusion cell, where above a certain threshold value of $J$, the assumption of negligible mass loss is no longer valid and rates cannot be deduced from the observed particle flux.

At the highest saturation levels, initial nucleation rates are extremely high and the time scales of mixing, nucleation, and coagulation become comparable. These points correspond to the extremely flat region in the observed number concentration vs saturation curves.

\section{A. Calculation of relative humidity and relative acidity}

The relative humidity and acidity of the combined streams is calculated based on a simple mass balance, the assumption of equilibrium in the bubblers at the temperature, and the pressure recorded inside each bubbler at a given condition.

The relative humidity after mixing is

$$
\mathrm{Rh}=\frac{p_{l} Y_{w} F_{h}}{p_{w}\left(T_{m}\right)\left[\left(1+Y_{w}\right) F_{h}+F_{d}+F_{a}\right]},
$$

where $F_{h}, F_{d}$, and $F_{a}$ are the humid, dry, and acidic flows, $p_{l}$ is the absolute pressure in the laboratory, $p_{w}\left(T_{m}\right)$ is the saturation vapor pressure of water at the temperature inside the mixer. $T_{m}$ is equal to the temperature in the nucleation and growth tube as measured by thermistor $T 4$ since mixing is isothermal. $Y_{w}$, the ratio of the moles of water to the moles of dry air, is

$$
Y_{w}=\frac{p_{w}\left(T_{w b}\right)}{p_{w b}-p_{w}\left(T_{w b}\right)} .
$$

Here $p_{w}\left(T_{w b}\right)$ is the saturation vapor pressure of water at the temperature inside the water bubbler and $p_{w b}$ is the actual measured pressure inside the water bubbler.

Likewise the relative acidity after mixing is

$$
\mathrm{Ra}=\frac{p_{l} p_{a}\left(T_{a b}\right) F_{a}}{p_{a b} p_{a}\left(T_{m}\right)\left[\left(1+Y_{w}\right) F_{h}+F_{d}+F_{a}\right]},
$$

where $p_{a b}, p_{a}\left(T_{a b}\right)$, and $p_{a}\left(T_{m}\right)$ are the actual acid bubbler pressure, the saturation vapor pressure of the acid at the temperature in the acid bubbler, and the saturation vapor pressure of acid at the temperature of the mixer. Furthermore the ratio of moles of acid to moles of air $Y_{a}$ is approximately equal to zero because the vapor pressure of the acid is on the order of one ppm.

\section{B. Acid purity}

The methanesulfonic acid used in all of the experiments was purchased from the Alfa Chemical Company with an assayed acid purity of $99.5 \%$ established by titration. This acid was not purified further and ranged in color from a pale straw color to light brown. On further discussion with the manufacturer of the acid, Penwalt Chemical Company, the major impurities were given as dimethyl disulfide at $<10$ $\mathrm{ppm}$ and methyl methane thiosulfonate at $<5 \mathrm{ppm}$ with some indication of chloromethyl sulfone at $<1 \mathrm{ppm}$. This is the same material used in the experiments by Kreidenweis $e t$ $a^{8} .^{8}$

\section{NUCLEATION RATES AND PARTICLE SIZE BEHAVIOR}

Experiments were performed at relative acidities of $0.33,0.15$, and 0.075 and relative humidities of 0.30 and 0.15 . The three temperaturcs investigated were 19,25 , and 
TABLE I. Experimental conditions investigated in the MSA-water nucleation experiments.

\begin{tabular}{cccc}
\hline \hline $\begin{array}{c}\text { Experiment } \\
\text { number }\end{array}$ & $\begin{array}{c}\text { Temperature } \\
\left({ }^{\circ} \mathrm{C}\right)\end{array}$ & $\begin{array}{c}\text { Relative } \\
\text { acidity, Ra }\end{array}$ & $\begin{array}{c}\text { Relative } \\
\text { humidity, Rh }\end{array}$ \\
\hline 16.02 & 29.6 & $0.329-0.332$ & $0.066-0.461$ \\
16.03 & 29.8 & $0.148-0.154$ & $0.083-0.655$ \\
16.04 & 29.9 & $0.075-0.076$ & $0.134-0.655$ \\
16.05 & 29.9 & $0.051-0.656$ & $0.301-0.307$ \\
16.06 & 29.9 & $0.075-0.656$ & $0.152-0.156$ \\
16.07 & 29.9 & $0.074-0.076$ & $0.151-0.654$ \\
16.08 & 18.9 & $0.328-0.331$ & $0.183-0.449$ \\
16.09 & 18.9 & $0.149-0.154$ & $0.277-0.641$ \\
16.10 & 18.9 & $0.075-0.078$ & $0.385-0.635$ \\
16.11 & 18.8 & $0.128-0.649$ & $0.294-0.297$ \\
16.12 & 18.9 & $0.363-0.652$ & $0.149-0.150$ \\
16.01 & 25.2 & $0.331-0.334$ & $0.084-0.457$ \\
16.13 & 24.6 & $0.327-0.330$ & $0.116-0.456$ \\
16.14 & 24.7 & $0.149-0.153$ & $0.199-0.648$ \\
16.15 & 24.9 & $0.075-0.076$ & $0.297-0.644$ \\
16.16 & 24.9 & $0.076-0.654$ & $0.297-0.317$ \\
16.17 & 25.0 & $0.291-0.650$ & $0.151-0.152$ \\
\hline \hline
\end{tabular}

$30^{\circ} \mathrm{C}$. Table I summarizes the conditions employed in the set of experiments presented here.

The measured total number concentrations of particles as functions of $\mathrm{Rh}$ are summarized in Figs. 4-6 for the three different temperatures. Horizontal error bars represent the computed uncertainty in the $\mathrm{Rh}$ due to uncertainties in the flow and temperature control. This uncertainty has been estimated as $\pm 5 \%$, due mainly to the uncertainties in flow calibrations which are each $\pm 3 \%$. Vertical error bars represent the range of values observed after the system had sta-

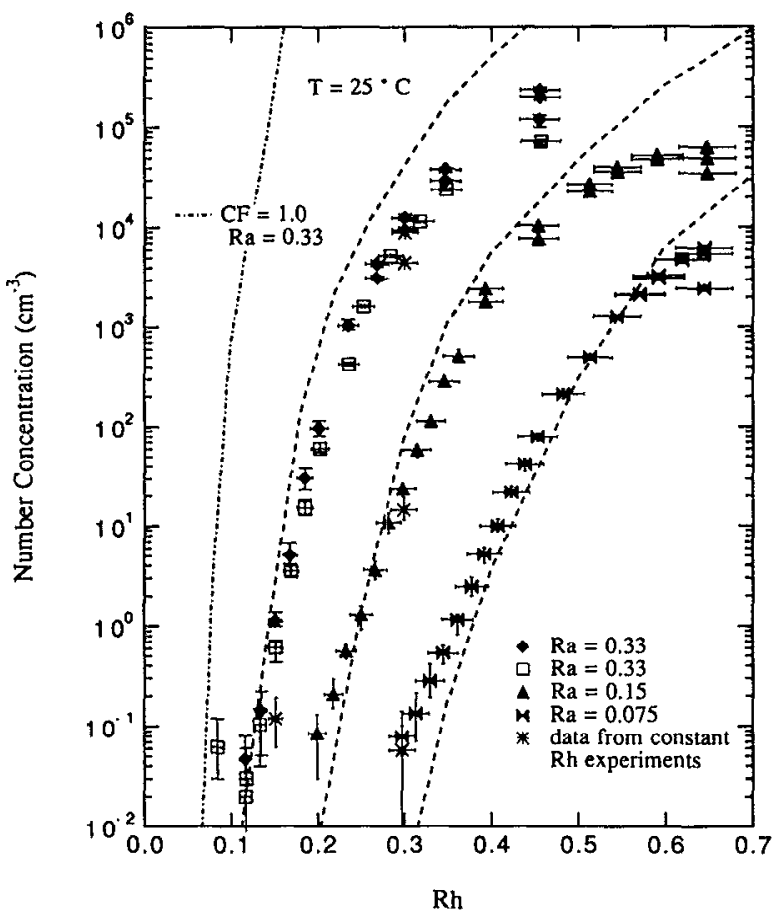

FIG. 4. Observed number concentrations as a function of relative humidity at $T=25^{\circ} \mathrm{C}$. Broken lines are the predicted number concentrations from the integral model using $\alpha_{p}=0.6, \alpha,=1.0$, and a correction factor, $C F=10^{-6}$.

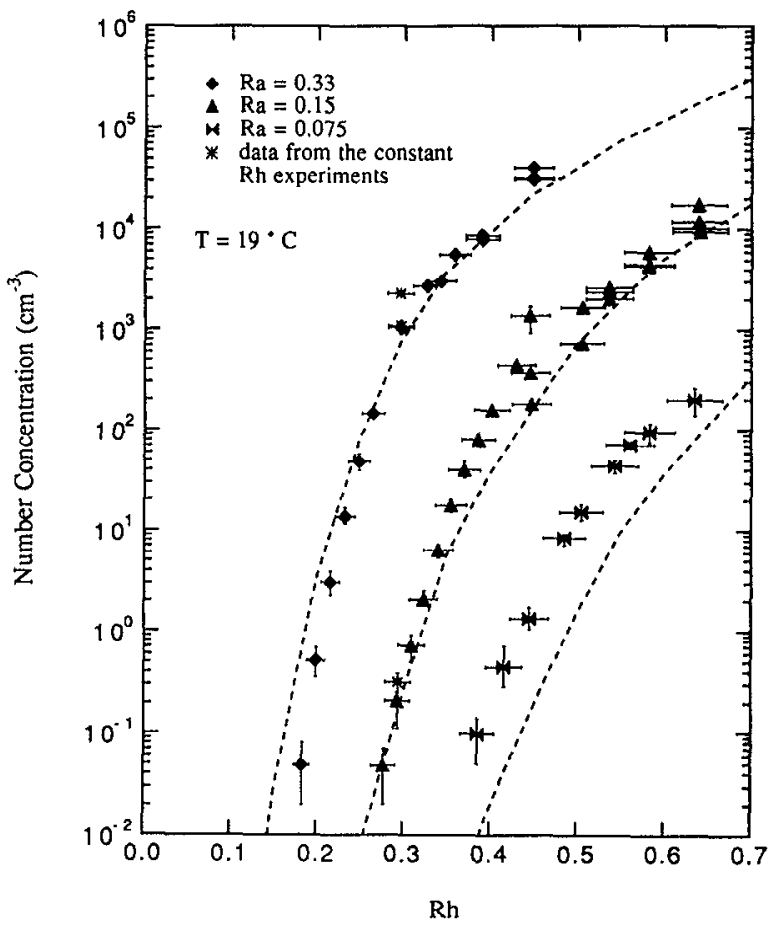

FIG. 5. Observed number concentrations as a function of relative humidity at $T=19^{\circ} \mathrm{C}$. Broken lines are the predicted number concentrations from the integral model using $\alpha_{p}=0.6, \alpha_{s}=1.0$, and $\mathrm{CF}=10^{-8}$.

bilized for a given condition, with the symbol located at the calculated mean value. The broken lines are the result of simulating the experiments and will be discussed subsequently. The equivalent curves generated for experiments in which $\mathrm{Rh}$ was constant and $\mathrm{Ra}$ was varied are available in the supplementary material submitted to PAPS. ${ }^{13}$

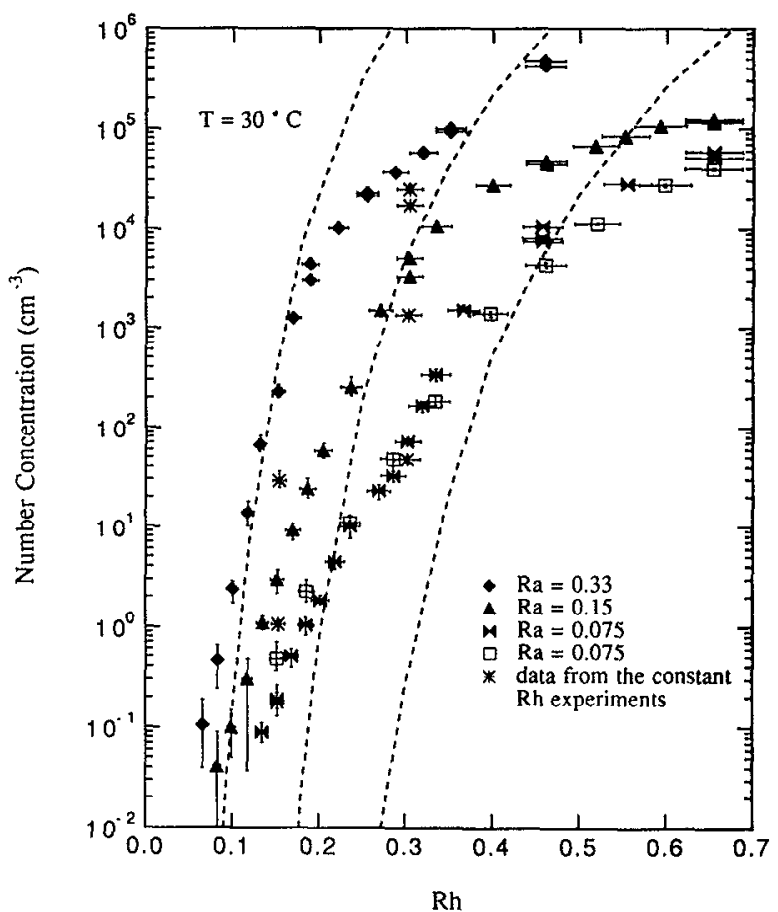

FIG. 6. Observed number concentrations as a function of relative humidity at $T=30^{\circ} \mathrm{C}$. Broken lines are the predicted number concentrations from the integral model using $\alpha_{p}=0.6, \alpha_{s}=1.0$, and $\mathrm{CF}=10^{-4}$. 
The extent to which the experiments are repeatable when working with a given batch of acid, is illustrated in Fig. 4 where data for the two runs at $\mathrm{Ra}=0.33$ were taken three days apart, and in Fig. 6 where data for the two runs at $\mathrm{Ra}=0.075$ were taken about $5 \mathrm{~h}$ apart. Consistency of the data set is very good and is illustrated in each of the figures by * symbols. In these figures data points collected during tests at constant relative humidity were added to the graphs of tests at constant relative acidity to show that the measured number concentration is insensitive to the way the particular combination of $\mathrm{Ra}$ and $\mathrm{Rh}$ was approached.

The total number concentration data follow the major trends predicted by binary nucleation theory. At low levels of one component particle concentrations less than $0.1 \mathrm{~cm}^{-3}$ are observed, which indicates that nucleation is not occurring at a measurable rate. At moderate degrees of saturation, a slight increase in the level of one of the components leads to an exponential increase in the total number of particles observed. This reflects the exponential increase in nucleation rate with saturation level that is characteristic of nucleation processes. As the saturation is increased further, the total number concentration curves begin to level off, indicating that the available acid vapor is rapidly depleted by condensation onto the newly formed particles and the nucleation process is quenched. With the production of large numbers of particles initially, condensation competes effectively for the remaining acid vapor and quickly reduces the relative nucleation rate. Thus large changes in the saturation level lead to relatively small changes in the total number of particles observed. Total particle concentrations generally vary from 5 to 7 orders of magnitude over the course of an experiment. On the steepest curves, this large increase is achieved over a change in relative saturation of only 0.3 . As relative acidity decreases, a higher level of relative humidity is required before particles are observed. Equivalent results are observed as relative humidity decreases. Figures $7-9$ summarize the relative saturation levels that correspond to nucleation rates of $J=0.01,1$, and $100 \mathrm{~cm}^{-3} \mathrm{~s}^{-1}$ that were derived from the total number concentration data at each temperature.

The increase in nucleation rates with temperature is clearly illustrated by comparing equivalent curves in Figs.

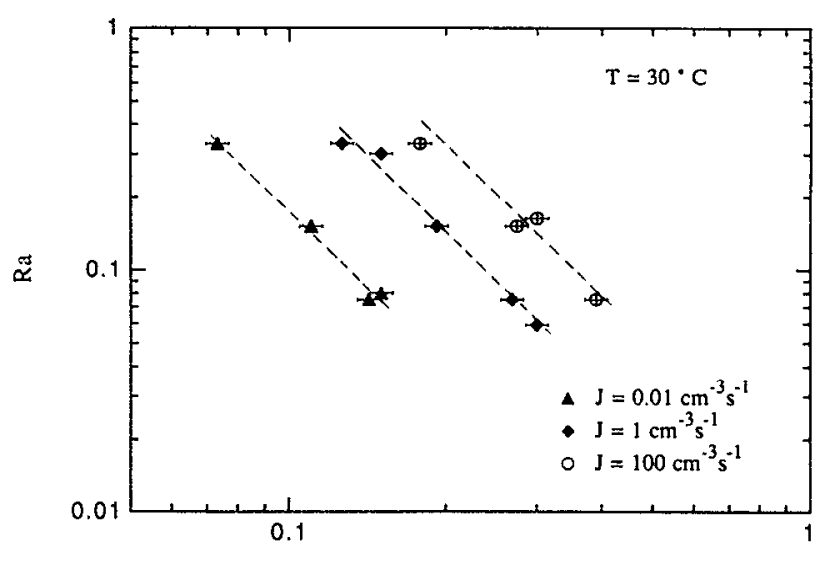

$\mathrm{Rh}$

FIG. 7. The variation of nucleation rates with saturation level for the MSAwater binary system at $J=0.01,1$, and $100 \mathrm{~cm}^{-3} \mathrm{~s}^{-1}$ and $T=30^{\circ} \mathrm{C}$.

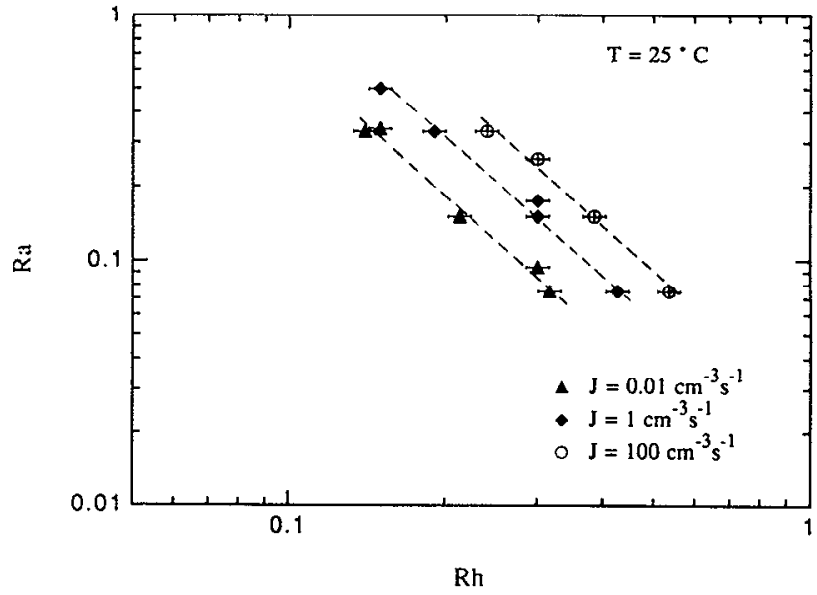

FIG. 8. The variation of nucleation rates with saturation level for the MSAwater binary system at $J=0.01,1$, and $100 \mathrm{~cm}^{-3} \mathrm{~s}^{-1}$ and $T=25^{\circ} \mathrm{C}$.

4-6, where a $5^{\circ} \mathrm{C}$ increase in temperature generally corresponds to a two order of magnitude increase in the nucleation rate. This increase in nucleation rate with temperature is consistent with observations in single component nucleation experiments.

Figures 10 and 11 illustrate typical particle size distributions. Figure 10 shows that as $\mathrm{Rh}$ increases at fixed Ra, particle size generally decreases. Physically, as the nucleation rate increases with $\mathrm{Rh}$ more particles are being formed from the same initial amount of acid. Thus there is simply less acid available for particle growth and the particle size must generally be smaller. On the other hand, Fig. 11 shows that as $\mathrm{Ra}$ increases at fixed $\mathrm{Rh}$, particle size first increases and later decreases. Here the situation is more complex. Although an increase in nucleation rate should decrease particle size, an increase in the amount of acid also allows for greater particle growth by condensation. Thus it appears that increases in condensation initially dominate and it is only at the highest saturation levels that increases in the nucleation rate produce enough particles to reduce the average particle size.

Many of the particle size curves display a bimodal distribution with a broad main peak and a smaller secondary peak

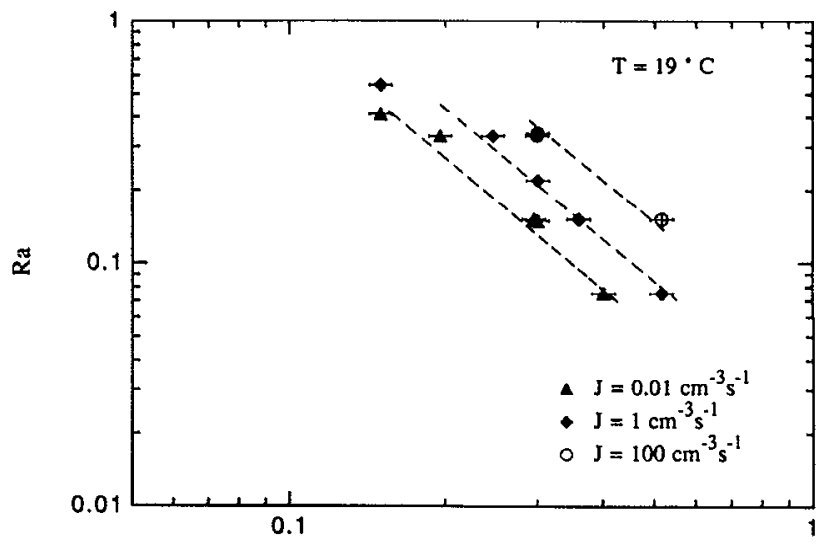

$\mathrm{Rh}$

FIG. 9. The variation of nucleation rates with saturation level for the MSAwater binary system at $J=0.01,1$, and $100 \mathrm{~cm}^{-3} \mathrm{~s}^{-1}$ and $T=19^{\circ} \mathrm{C}$. 

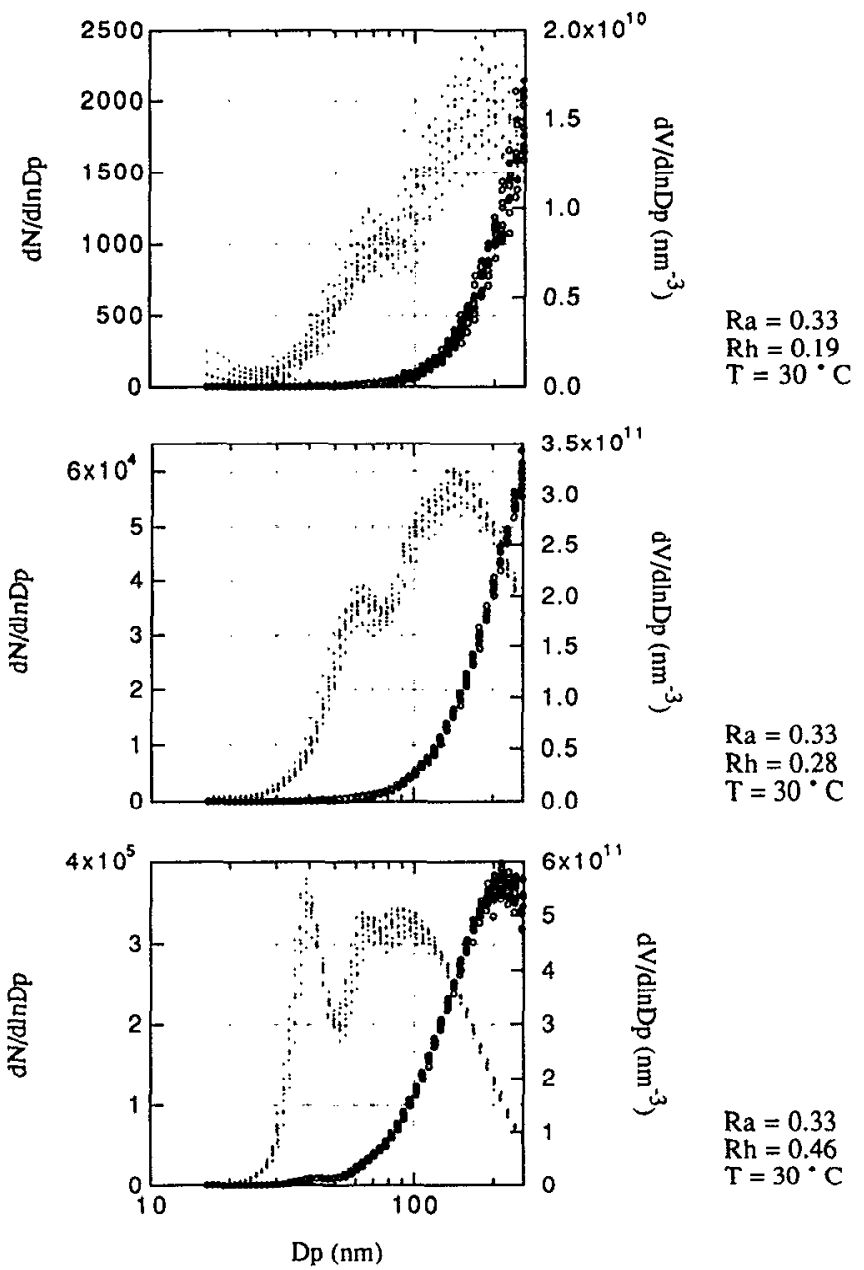

$\mathrm{Ra}=0.33$
$\mathrm{Rh}=0.46$

$\mathrm{T}=30^{\circ} \mathrm{C}$

FIG. 10. The observed change in the particle size distributions with increasing nucleation rates due to increases in $R h$.

located at approximately one half the diameter of the main peak. The main peak is believed to represent those particles that are formed by nucleation between MSA and water vapor which then grow by the subsequent condensation of MSA and water in the nucleation and growth tube. Because of the great excess of water present, particles are in equilibrium with the local relative humidity at all times, and growth is limited by the number of acid molecules added to the droplet. The main peak is always present. The second peak is most pronounced at high saturation levels of both components and at the highest temperatures. In about half of the distributions this second peak is not present.

From the measured number distributions, $d N / d \ln D_{p}$, volume distribution, $d V / d \ln D_{\rho}$, curves were constructed. The peak diameter of the volume distribution curves, which is equivalent to the peak diameter in the mass distribution, was within the measuring range of the DMA for about half of the distributions. This value is important because it is predicted by the model that will be used to simulate the experiments. Figures 12 and 13 further illustrate the behavior of the peak diameter in the number distribution under varying conditions of relative humidity and relative acidity. The broken lines are intended as visual aids only and do not represent numerical fits of the data points. In Fig. 12 the largest

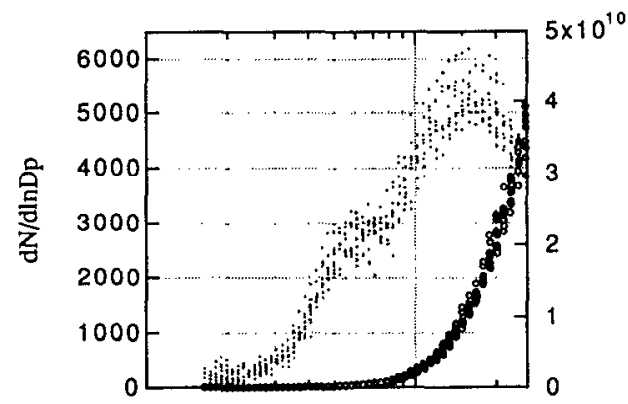

产

$\mathrm{Rh}=0.30$

$\mathrm{Ra}=0.26$ $\mathrm{T}=30^{\circ} \mathrm{C}$

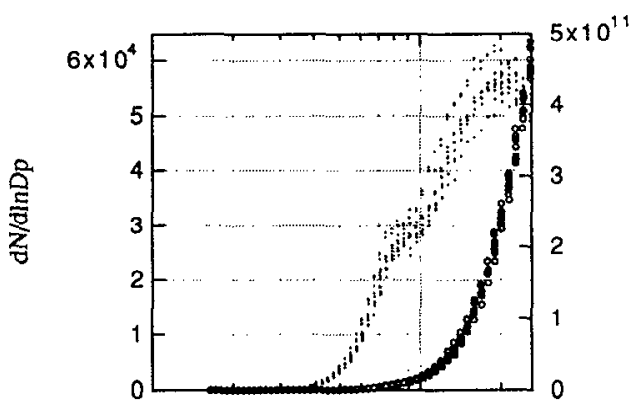

童

$\mathrm{Rh}=0.30$

$\mathrm{Ra}=0.51$

$\mathrm{T}=30^{\circ} \mathrm{C}$

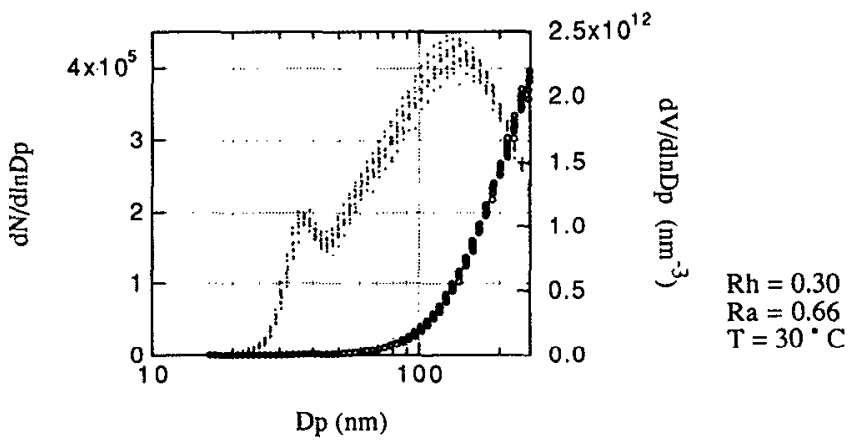

FIG. 11. The observed change in the particle size distributions with increasing nucleation rates due to increases in $\mathrm{Ra}$.

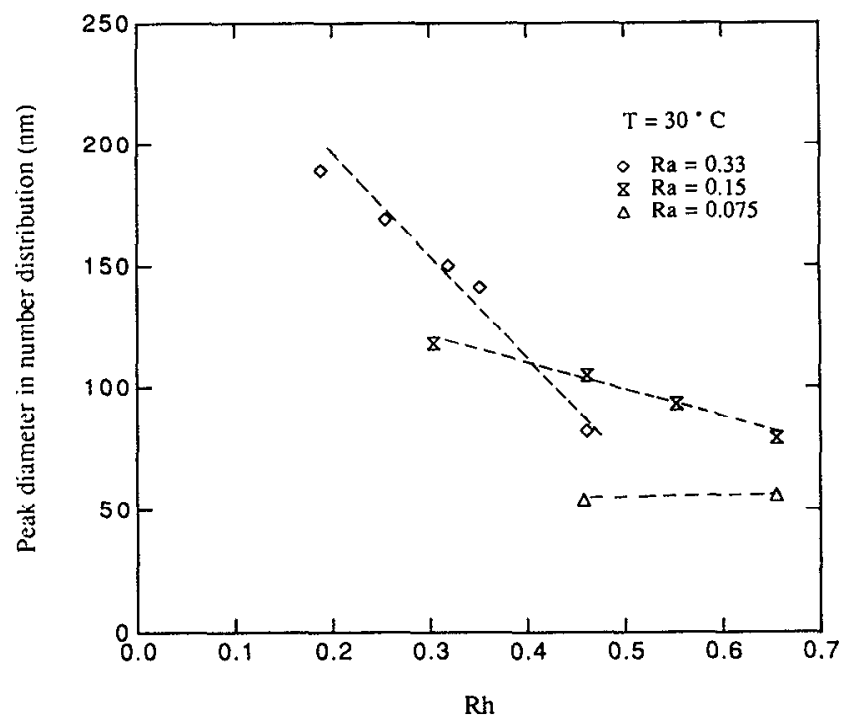

FIG. 12. Variation in the peak diameter of the number distribution with $R h$ for three values of $\mathrm{Ra}$ at $T=30^{\circ} \mathrm{C}$. The broken lines indicate the trend in the data only. 


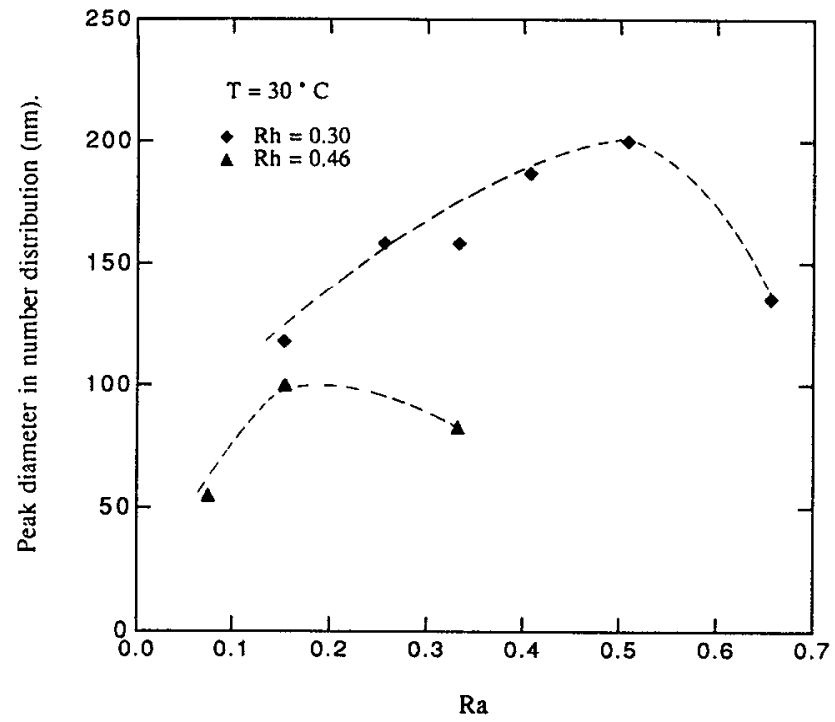

FIG. 13. Variation in the peak of the number distribution with Ra for two values of $\mathrm{Rh}$ at $T=30^{\circ} \mathrm{C}$. The broken lines indicate the trend in the data only.

changes in peak diameter are found in the curve for $\mathrm{Ra}=0.33$. By comparing the conditions of these tests to the appropriate number concentration curves, it is clear that the larger decrease in diameter at $\mathrm{Ra}=0.33$ corresponds to a larger increase in number concentration than is observed for the conditions at $\mathrm{Ra}=0.075$, where essentially no change in peak diameter is observed.

The effect of changing $\mathrm{Ra}$ for fixed $\mathrm{Rh}$ is illustrated for $T=30^{\circ} \mathrm{C}$ in Fig. 13. The curves at two levels of Rh exhibit the same type of behavior, an increase in peak diameter with an increase in $\mathrm{Ra}$ followed by a sharp decrease at the highest level of $\mathrm{Ra}$. As in Fig. 12, the particles produced at higher relative humidity are smaller. This behavior was also observed at $T=19$ and $25^{\circ} \mathrm{C}$.

Although the model used predicts only a single mass average diameter, Fig. 14 shows that for the range of data collected, the peak in the mass distribution is related to the peak in the number distribution in a straightforward manner. Thus the curves illustrating the behavior of the number distribution peaks should be equivalent to the behavior in the mass distribution peaks with a suitable change in the scaling. In addition, the slope of this curve gives an estimate of the polydispersity factor $\alpha_{p}$. This factor will be required in the integral model equation describing the condensation of the acid vapor onto the existing aerosol. Because the model assumes a monodisperse aerosol, condensation will be overpredicted if $\alpha_{p}$ is set equal to 1 . Okuyama et al. ${ }^{11}$ showed that the poydispersity factor $\alpha_{p}=D_{p N} / D_{p m}$ where $D_{p N}$ and $D_{p m}$ are the number and mass average diameters, respectively. In Fig. 14 this corresponds to the slope of the data and is about $\alpha_{p}=0.6$.

\section{INTEGRAL MODEL OF NUCLEATION AND GROWTH}

The measured total number concentrations do not yield nucleation rates directly. Rather they measure the total number of particles that result from the competition be-

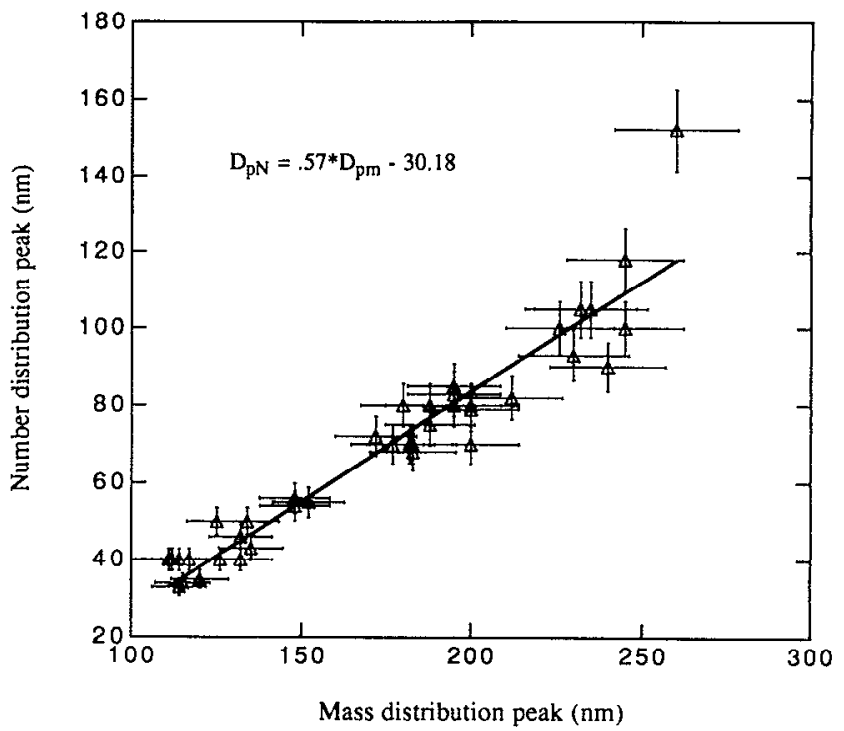

FIG. 14. Variation in the peak of the number distribution with the peak in the mass distribution. The slope of the line is an estimate of the polydispersity factor, $\alpha_{\rho}$.

tween nucleation and condensation along the length of the nucleation and growth tube. When the total number of particles is small, condensation should not change the saturation level of the acid significantly, and the nucleation rate may be calculated from the total number concentration by dividing by the length of time over which nucleation is occurring. In order to determine when condensation begins to dominate and to compare experimental results to the predictions of theory over the entire range of experimental results, it is necessary to integrate the changes occurring in the gas and aerosol phases along the length of the nucleation and growth tube. The fact that the total number of particles is a strong function of the nucleation rate provides the basic validity of the experimental approach; it is expected that simulating the experiments should yield sensitive information regarding the adequacy of the binary nucleation rate expression over the range of conditions studied.

An integral nucleation and growth model that predicts the basic variables of interest, i.e., the total number of particles formed and the mass average particle diameter, was developed by Okuyama et al. ${ }^{11}$ and is the model applied to these experiments. The model describes the saturation level of the acid in the vapor phase $S_{a}$, the total number of particles $N_{a}$, and the total mass of acid in the aerosol phase $M_{a}$, and will therefore be referred to as the SNM model. The model assumes that the formation and growth of the aerosol does not change the amount of water present because the vapor pressure of the water is much higher than that of the acid.

The three differential equations that describe the evolution of the aerosol in the absence of coagulation and wall losses from either the vapor or aerosol phase are

$$
\begin{aligned}
\frac{d S_{a}}{d t} & =\frac{d R_{a}}{d t}=\frac{-\left(N_{A} g^{*} J+R_{c}\right) R T}{p_{a}^{0}}, \\
\frac{d M_{a}}{d t} & =M_{m a}\left(g^{*} J+R_{c}\right),
\end{aligned}
$$




$$
\frac{d N_{a}}{d t}=J,
$$

where $N_{A}$ is Avogadro's number, $g^{*}$ is the number of acid molecules in a critical cluster, $J$ is the rate of binary nucleation, $R_{c}$ is the rate of condensation, and $M_{w a}$ is the molecular weight of the acid. The equations are integrated for $18 \mathrm{~s}$, which corresponds to the residence time of the nucleation and growth tube under the conditions employed. The mass of each droplet at any point in the tube is calculated by taking the total mass of acid in the aerosol phase, dividing by the total number of particles and then adding water to achieve equilibration at the local relative humidity. The mass and composition of the droplet determine the mass average diameter. The property data correlations for the MSA-water binary used in the simulations are those developed by Kreidenweis et al. ${ }^{8}$

\section{A. The rate of binary nucleation}

The generalized rate expression for binary nucleation is

$$
J=C \exp \left(-\Delta G^{*} / k T\right),
$$

where $\Delta G^{*}$ is the free energy of formation of the critical cluster from the vapor phase and $C$ is a slowly varying preexponential factor. The critical cluster corresponds to the saddle point in the cluster free energy surface. Later work refined the original expression of Reiss ${ }^{2}$ to better reflect the kinetics of the process, ${ }^{14}$ to locate the saddle point more accurately, ${ }^{15-17}$ and to reffect the effect due to the presence of hydrates in the gas phase. ${ }^{18-20}$

Hydrate formation can have a relatively large effect on the nucleation rate by changing the shape of the free energy surface and therefore the location and value of $\Delta G$ at the saddle point. Traditionally, the free energy surface is described as a function of the number of acid molecules $n_{1}$, and the number of water molecules $n_{2}$, by

$$
\Delta G\left(n_{1}, n_{2}\right)=n_{1}\left(\mu_{1}-\phi_{1}\right)+n_{2}\left(\mu_{2}-\phi_{2}\right)+\sigma A,
$$

where $\mu$ and $\phi$ are the chemical potentials of the species in the liquid and gas phases, $\sigma$ is the surface tension of the cluster, and $A$ is the surface area of the cluster.

Jaecker-Voirol and Mirabel ${ }^{19}$ showed that the free energy surface $\Delta G$ could be modified to produce a new surface $\Delta G^{\prime}$, reflecting the presence of hydrates. Their expression relating the two surfaces is

$$
\begin{aligned}
& \exp \left(\frac{-\Delta G^{\prime}}{k T}\right) \\
& \quad=\left[\frac{1+K_{1}^{\prime} p_{w+}+K_{1}^{\prime} K_{2}^{\prime} \cdots\left(p_{w}\right)^{h}}{1+K_{1}^{\prime} p_{1+}+K_{1}^{\prime} K_{2}^{\prime} \cdots\left(p_{1}\right)^{h}}\right]^{n_{2}} \exp \left(\frac{-\Delta G}{k T}\right) .
\end{aligned}
$$

Here $p_{w}$ is the partial pressure of water vapor above a droplet of composition $n_{1}$ waters and $n_{2}$ acids, and $p_{1}$ is the vapor pressure of water in the system. The values of $K_{h}^{\prime}$ are the equilibrium constants for the reactions

$$
\mathrm{H}_{2} \mathrm{O}+\mathrm{ACID} \cdot h \mathrm{H}_{2} \mathrm{O} \leftrightarrow \mathrm{ACID} \cdot(h+1) \mathrm{H}_{2} \mathrm{O}
$$

and are found by looking at the free energy change on addition of a water molecule,

$$
K_{h}^{\prime}=\exp \left(\frac{-\Delta G_{h}^{0}}{k T}\right)
$$

with

$$
\Delta G_{h}^{0}=k T \ln p_{w}+\frac{2 \sigma \nu_{1}}{r} .
$$

$p_{w}$ is expressed in atmospheres, $\sigma$ is the surface tension, $v_{1}$ is the partial molecular volume of water (partial molar volume $/ N_{A}$ ), and $r$ is found from

$$
{ }_{3}^{4} \pi r^{3}=\left(n_{1}+n_{2}\right) v,
$$

where $v$ is the molecular volume of the mixture. ${ }^{21}$ The first ten hydration constants were calculated by Jaecker-Voirol and Mirabel ${ }^{19}$ for sulfuric acid and water. Table II shows the equivalent values for the MSA-water binary at $25^{\circ} \mathrm{C}$ calculated using Eqs. (11)-(13). With $K_{1}^{\prime}=142$ for MSA vs 1360 for sulfuric acid, the effect of hydration is not as strong for MSA, but it is still significant, especially at higher relative humidities.

Hydrate distributions were calculated for relative humidities of $0.1,0.5$, and 1.0. Above $R h=0.10$, the concentration of hydrates containing one acid molecule becomes significant with respect to the total acid concentration. The concentration of hydrates containing 2 or 3 acid molecules is always many orders of magnitude smaller than the equivalent hydrate containing only one acid molecule, and may therefore be ignored.

Including the effect of hydrates, the general nucleation rate expression still takes the form

$$
J=C \exp \left(-\Delta G^{*} / k T\right),
$$

but now $\Delta G^{*}$ is the saddle point of the modified free energy surface. The frequency factor $C$ previously had the form

$$
C=\frac{\beta_{2} A^{*} N_{1} Z}{\sin ^{2} \phi},
$$

where $\beta_{2}$ is the rate of acid impingement, $A^{*}$ is the surface area of the critical nucleus, $N_{1}$ is the number density of water vapor, and $Z$ is the nonequilibrium factor, equivalent to the Zeldovitch factor in single component nucleation. The angle $\phi$ is the angle between the direction of growth and the $n_{1}$ axis. In cases when the critical nucleus is not dilute with respect to either component, Jaccker-Voirol and Mirabel ${ }^{20}$ have suggested that this angle may be approximated by

$$
\tan \phi=\frac{n_{2}^{*}}{n_{1}^{*}+n_{2}^{*}} .
$$

It can be shown that this assumption is valid for the conditions of interest in the MSA-water system. To account for hydrates, the term $\beta_{2} A$ * is replaced by

$$
\tau=(8 \pi k T)^{1 / 2} \sum_{h=0}^{h=h_{\max }} \delta^{2} \gamma^{-1 / 2} N_{h},
$$

TABLE II. Values of the first $10 K_{h}^{\prime}$ constants for MSA-water at $25^{\circ} \mathrm{C}$.

\begin{tabular}{ccccccccccc}
\hline \hline$h$ & 1 & 2 & 3 & 4 & 5 & 6 & 7 & 8 & 9 & 10 \\
\hline$K_{h}$ & 142.9 & 31.2 & 15.6 & 10.7 & 8.80 & 7.79 & 7.24 & 6.91 & 6.71 & 6.59 \\
\hline
\end{tabular}




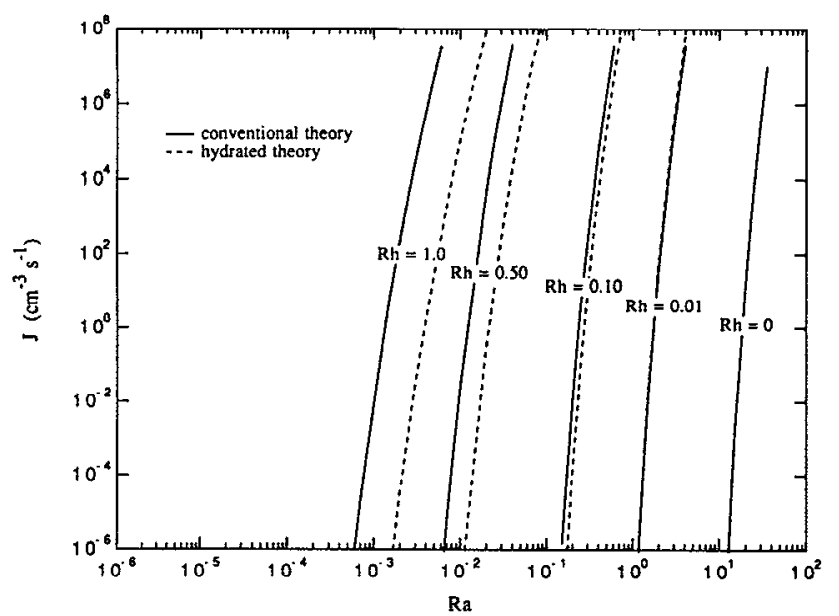

FIG. 15. The reduction in nucleation rates as a function of relative humidity when the effect of hydrates is included in the classical nucleation theory.

where $\delta$ is the sum of the radii of the critical nucleus and the hydrate, $\gamma$ is the reduced mass of the critical nucleus and the hydrate, and $N_{h}$ is the number density of the hydrates containing $h$ water molecules.

The effect that hydration has on the nucleation rate in the region of interest for the experiments carried out here, is illustrated in Fig. 15, where rates calculated without accounting for hydrates are compared to those predicted by the hydrated theory. At $R h=0.10$, the rate is reduced by about 2 orders of magnitude, while at $\mathrm{Rh}=1.0$ $J_{\text {unhydr }} / J_{\text {hydr }} \cong 10^{-6}$. The value of $Z$ has been taken as $0.25 .^{20}$ The saddle point of the free energy surface has been determined by a numerical search that limits clusters to integral numbers of water and acid molecules.

\section{B. Rate of condensation}

Once particles have formed in the gas phase, nucleation must compete with condensation, which will quickly dominate the mass transfer process from the gas to the aerosol phase. The condensation rate is approximated by a continuum expression which is modified for noncontinuum effects by an expression due to Dahneke, ${ }^{22}$

$$
\begin{aligned}
R_{c}= & 2 \pi D_{A B} P_{a}^{0} \int_{D_{p^{*}}}^{\infty} D_{p} n\left(D_{p}\right)\left[S_{a}-a_{a}\right. \\
\times & \left.\exp \left(\frac{4 \sigma \bar{v}_{a}}{D_{p} R T}\right)\right] f(K n) d D p, \\
= & \alpha_{p}\left\{2 \pi D _ { A B } p _ { a } ^ { 0 } \overline { D } _ { p } \left[S_{a}-a_{a}\right.\right. \\
& \left.\left.\times \exp \left(\frac{4 \sigma \bar{v}_{a}}{\bar{D}_{p} R T}\right)\right] f(\overline{K n})\right\} N,
\end{aligned}
$$

with the average Knudsen number, $\overline{K n}=\lambda_{A B} / \bar{D}_{p}, \bar{D}_{p}$ the average particle diameter, and

$$
f(\overline{K n})=\frac{(1+\overline{K n})}{\left(1+2 \overline{K n}(1+\overline{K n}) / \alpha_{s}\right)} .
$$

Here $D_{A B}$ is the binary diffusion coefficient of acid gas in air, $a_{a}$ is the acid activity, $\bar{v}_{a}$ is the partial molar volume of the acid, and $\lambda_{A B}$ is the mean free path of the acid molecules in air. $\mathbf{A}$ factor $\alpha_{s}$ has been added to account for the sticking probability of an acid molecule, and a second factor $\alpha_{p}$ accounts for the polydispersity of the the aerosol. Because the aerosol is modeled as being monodisperse, condensation will be overpredicted if $\alpha_{p}$ is set equal to 1 . However, from the data of $D_{p N}$ vs $D_{p m}$ it is possible to estimate a value for $\alpha_{p}=D_{p N} / D_{p m}$ as about 0.6. The term $\alpha_{s}$ represents the sticking probability or accommodation coefficient of an acid molecule as it strikes the surface of a growing droplet. The value of this parameter has not been measured for MSA. Recent work by Van Dingenen ${ }^{23}$ concluded the value of $\alpha_{s}$ for sulfuric acid lies in the range $0.024<\alpha_{s}<0.064$ with a geometric mean value of 0.04 , but in the absence of any other data $\alpha_{s}=1.0$ will be used in the MSA modeling.

If the presence of hydrates is included in the nucleation calculation, their effect on the rate of condensation should also be considered. The change in the average value of $D_{A B}$ and $\lambda_{A B}$ due to hydrates is of greatest concern. Table III summarizes the estimated values of these parameters for the first five hydrates, and weights them with respect to the relative number distribution of the hydrates at relative humidities of 0.50 and 0.10 to estimate an average value. The diffusivities were estimated using the Chapman-Enskog equation with the first order approximation of the collision parameter, $\Omega=1,^{24}$

TABLE III. Diffusivity, mean speed and mean free path of the MSA- $\mathrm{H}_{2} \mathrm{O}$ hydrates.

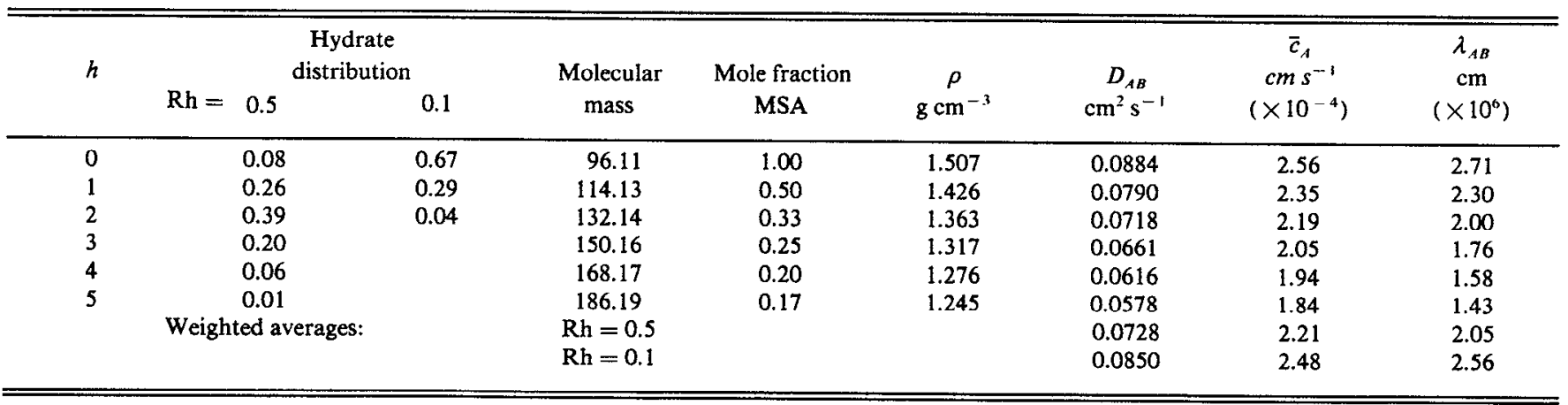




$$
D_{A B}=\frac{0.00266 T^{3 / 2}}{p M_{A B}^{1 / 2} \sigma_{A B}^{2}}
$$

with $p$, the pressure in bars, $M_{A B}=2\left[1 / M_{A}+1 / M_{B}\right]^{-1}$ and $\sigma_{A B}$ the characteristic length is given by $\sigma_{A B}=\left(\sigma_{A}+\sigma_{B}\right) / 2$ in angstroms. The value of $\sigma_{B}$ for air was taken as $3.711 \AA$ from Reid et $a l^{24}$ and the values of $\sigma_{A}$ for MSA and the hydrates was estimated from the molecular volume of the liquid phase. The mean free path $\lambda_{A B}$ may be estimated for the dilute species $A=$ free acid molecule or hydrate $\mathrm{as}^{25}$

$$
\begin{aligned}
& \lambda_{A B}=\frac{32 D_{A B}}{3 \pi \bar{c}_{A}\left(1+M_{A} / M_{B}\right)}, \\
& \bar{c}_{A}=\left(8 R T / \pi M_{A}\right)^{1 / 2},
\end{aligned}
$$

where $\bar{c}_{A}$ is the mean speed of the hydrate.

Although the presence of hydrates does change the average value of the diffusivity, the change is only on the order of $20 \%$, which is well within the uncertainty of the estimation method. The only available experimental estimate of the diffusivity of MSA is due to Tang. ${ }^{26}$ When measuring the vapor pressure of MSA, the value of a temperature independent parameter

$$
b=\left(\frac{\rho R T_{0}^{2}}{8 M_{H} D_{0}}\right)
$$

was estimated as $1.7856 \times 10^{8}$ Torr $\mathrm{K} \mathrm{s} \mathrm{cm}^{-2}$. With a value of $R=6.237 \times 10^{4}$ Torr $\mathrm{cm}^{3} \mathrm{gmol}^{-1} \mathrm{~K}^{-1}$, this gives $D_{A B}=0.06 \mathrm{~cm}^{2} \mathrm{~s}^{-1}$ at $T_{0}=298 \mathrm{~K}$. The estimate is within $30 \%$ of the theoretical value, but because the experiment was not designed to measure $D_{A B}$, the theoretical value will be used in the model calculations.

\section{Effect of temperature on nucleation rates, changes in property data}

Changes were made in the MSA property correlations developed by Kreidenweis $e t a l^{8}$ to allow for variation with temperature. Density data were taken from Teng and Lenzi ${ }^{27}$ and extrapolated to give $\rho_{30} / \rho_{25}=\rho_{25} / \rho_{20}=1.002$ for pure MSA. The variation of vapor pressure with temperature was taken from the correlation presented by Tang and Munkelwitz. ${ }^{28}$ Diffusivity was varied with temperature as $D i j=D_{i j}^{0}\left(T / T^{0}\right)^{2}$ as suggested by Tang and Munkelwitz. ${ }^{28}$

The variation of surface tension with temperature for pure MSA was estimated using a group contribution meth$\mathrm{od}^{21}$ and was found to give $\sigma_{25} / \sigma_{30}=1.007$ and $\sigma_{19} / \sigma_{25}=1.009$. This was combined with the known variation in the surface tension of water with temperature and the variation of surface tension with composition at $25^{\circ} \mathrm{C}$, to give an estimate of surface tension over the range of temperatures and compositions required for modeling the experiments. When the change in surface tension with temperature was estimated for sulfuric acid and subsequently compared to the measured values, the ratio of estimated/measured was approximately 3 . Thus the estimated change in surface tension with temperature for MSA may be somewhat high.

To vary the activity $a_{i}$ with temperature, the partial molar heats of mixing $\bar{h}_{i}$, are required. The first approximation for this change is then given $b y^{24}$

$$
\ln \left(a_{i}(T)\right)=\ln \left(a_{i}\left(T^{0}\right)\right)-\frac{\bar{h}_{i}}{R}\left(\frac{1}{T}-\frac{1}{T^{0}}\right) .
$$

The change in activity coefficients with temperature is important because the increase in nucleation rates with temperature due to decreases in surface tension and increases in the vapor pressure may be offset in part, or entirely, by an increase in the activity coefficient. No heat of mixing data are available for the MSA-water binary system. As a first estimate therefore, the values for sulfuric acid $^{29}$ have been used.

Figure 16 shows the results of temperature variation on the calculated nucleation rates for relative humidities of 0.50 and 0.10 . The sensitivity of the rate calculations to the extrapolated physical properties is illustrated by letting the surface tension variation of pure MSA be reduced to $\frac{1}{3}$ of the estimated change and the heats of mixing be reduced by $\frac{1}{2}$. These changes show that, despite the uncertainty in extrapolation, the calculated nucleation rates at 20 and $30^{\circ} \mathrm{C}$ are known to within a factor of 10 , relative to the nucleation rates at $25^{\circ} \mathrm{C}$. The major effect of temperature is to steepen the rate curves, thus the curves must cross at some value of $\mathrm{Ra}$ and $\mathrm{Rh}$.
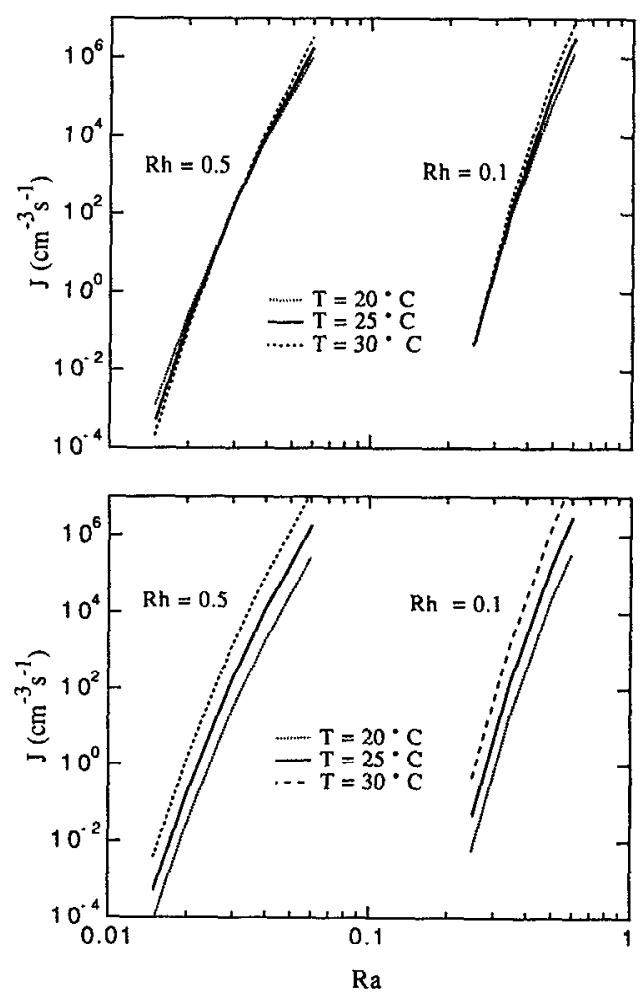

FIG. 16. The changes in the nucleation rate with temperature as predicted by binary nucleation theory and the sensitivity of these to uncertainties in the property values. (a) The temperature dependence of the surface tension of MSA has been estimated using a group contribution method and the heats of mixing are those of sulfuric acid. (b) The temperature dependence of the surface tension of MSA has been estimated as $\frac{1}{3}$ of that estimated by the group contribution method and the heats of mixing are $\frac{1}{2}$ of the values for sulfuric acid. 


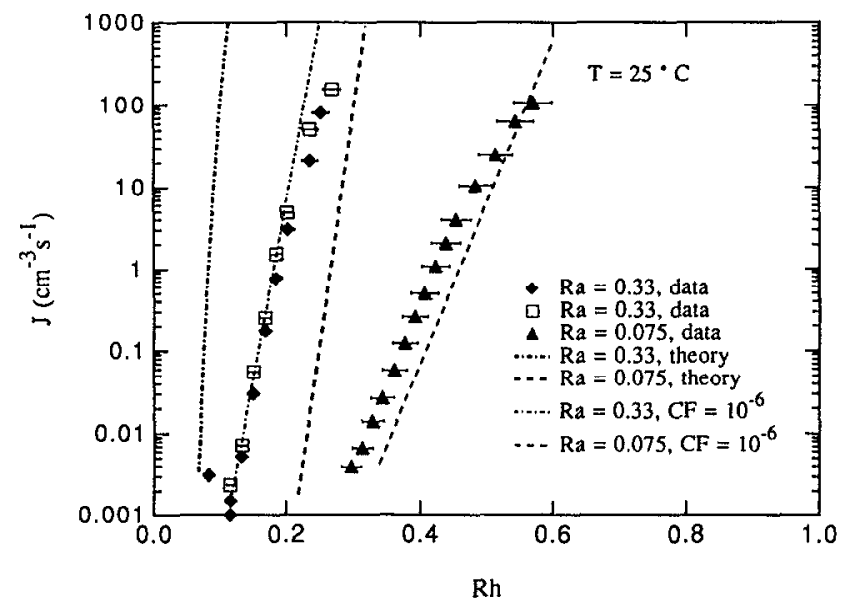

FIG. 17. A comparison of the expcrimental nucleation rates with classical binary nucleation theory and with the empirically corrected theoretical curves.

\section{COMPARISON OF THE EXPERIMENTAL DATA WITH BINARY NUCLEATION THEORY AND THE INTEGRAL MODEL}

The experimental nucleation rate data were first simulated at $25^{\circ} \mathrm{C}$, where physical property data are well known. As illustrated in Fig. 17, nucleation rate data for $\mathrm{Ra}=0.33$ and 0.075 do not agree with classical binary nucleation theory by several orders of magnitude. This was also the case for the data at $T=19$ and $30^{\circ} \mathrm{C}$.

The use of a correction factor to reconcile the differences between observed and predicted nucleation rates has been a reasonably successful approach and Table IV summarizes typical values observed for $J_{\text {expt }} / J_{\text {theor }}$ in both unary and binary nucleation. For $T=25^{\circ} \mathrm{C}$, a single correction factor of $1 \times 10^{-6}$ is found to adequately fit the MSA-water rate data Fig. 17, as well as all of the total number concentration data, Fig. 4. Similarly, as illustrated in Fig. 5, the
$T=19^{\circ} \mathrm{C}$ data are very well described by a correction factor of $1 \times 10^{-8}$. Only the $T=30^{\circ} \mathrm{C}$ data, Fig. 6, are not easily fit using this method, with a large mismatch between the data curves and the model still apparent even when the best correction factor, $1 \times 10^{-4}$, is used. We can think of no reason to reject the $T=30^{\circ} \mathrm{C}$ data as less reliable than the data at 25 or $19{ }^{\circ} \mathrm{C}$. Although the discrepancy is greatest at total number concentrations of less than $1 \mathrm{~cm}^{-3}$, a region where repeatability is generally more difficult, the data for $\mathrm{Ra}=0.075$ includes the results of two experiments that agree well even in this region. Indeed the mismatch arises because the model predicts very similar slopes at $30^{\circ} \mathrm{C}$ for $\mathrm{Ra}=0.33$ and $\mathrm{Ra}=0.075$, while, as illustrated in Fig. 6, the experiments show these slopes are different.

Despite these difficulties, the excellent predictions generated at the two lower temperatures justifies the use of this approach as appropriate in light of the simplicity of the overall model. Of interest is the behavior of the ratio $J_{\text {expt }} / J_{\text {theor }}$ as a function of temperature. Previous work has found that this ratio generally decreases with an increase in temperature, while this work shows that in the MSA-water system the opposite is true. Even if the rate calculations at $T=19$ and $30^{\circ} \mathrm{C}$ are incorrect by an order of magnitude due to uncertainties in the property data, a reasonable maximum uncertainty as estimated previously, this trend would still hold.

Given the correction factor at each temperature, nucleation rate profiles and saturation levels were calculated along the length of the nucleation and growth tube to confirm that the assumptions made that these were relatively constant at particle concentrations $\leqslant 10^{3}$, were indeed acceptable. Figure 18 illustrates the variation of the normalized nucleation rate, $J / J^{\circ}$, and the normalized relative acidity, $\mathrm{Ra} / \mathrm{Ra}^{0}$, along the length of the flow tube for $\mathrm{Ra}=0.33$ and initial nucleation rates of $J^{0}=10$ and $100 \mathrm{~cm}^{-3} \mathrm{~s}^{-1}$. Certainly at $J^{0}=10 \mathrm{~cm}^{-3} \mathrm{~s}^{-1}$, the nucleation rate after $18 \mathrm{~s}$ of integration time is better than $80 \%$ of the initial rate and the acid saturation level has dropped by less than $2 \%$. Lower values

TABLE IV. Experimental correction factors to classical nucleation theory.

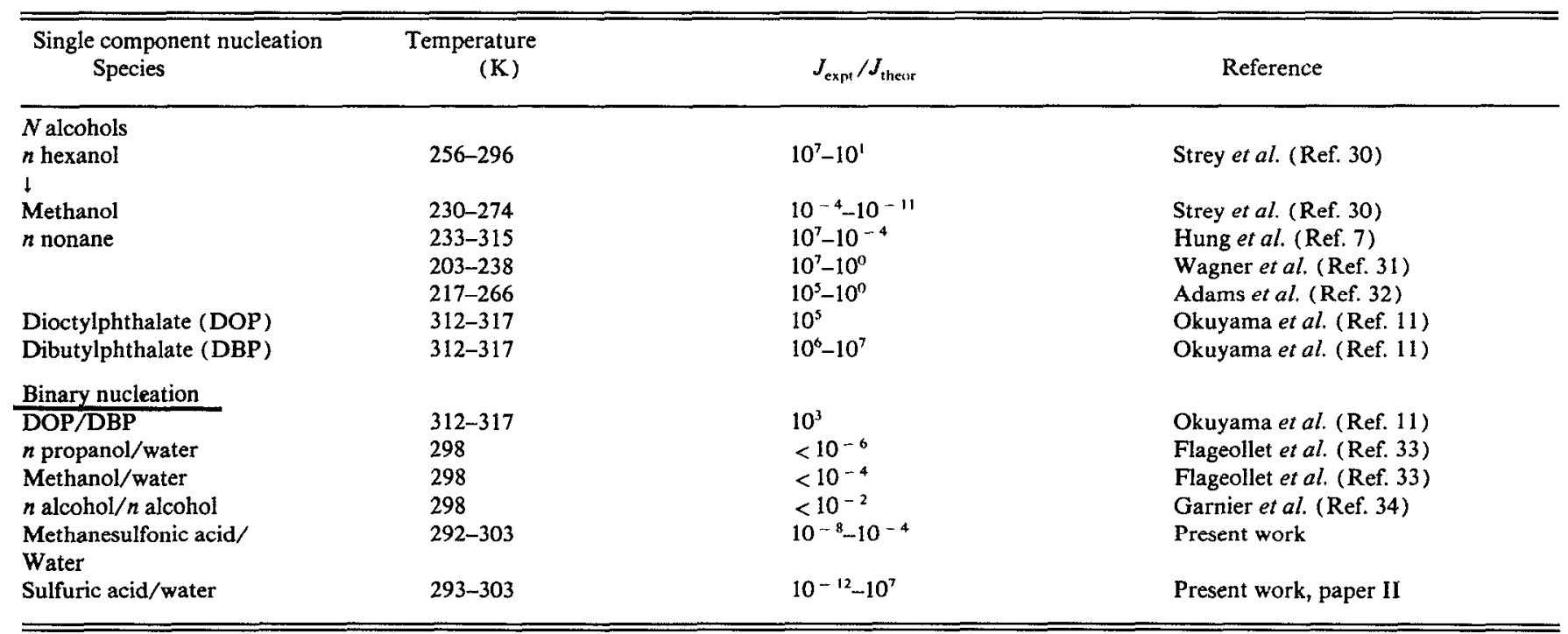



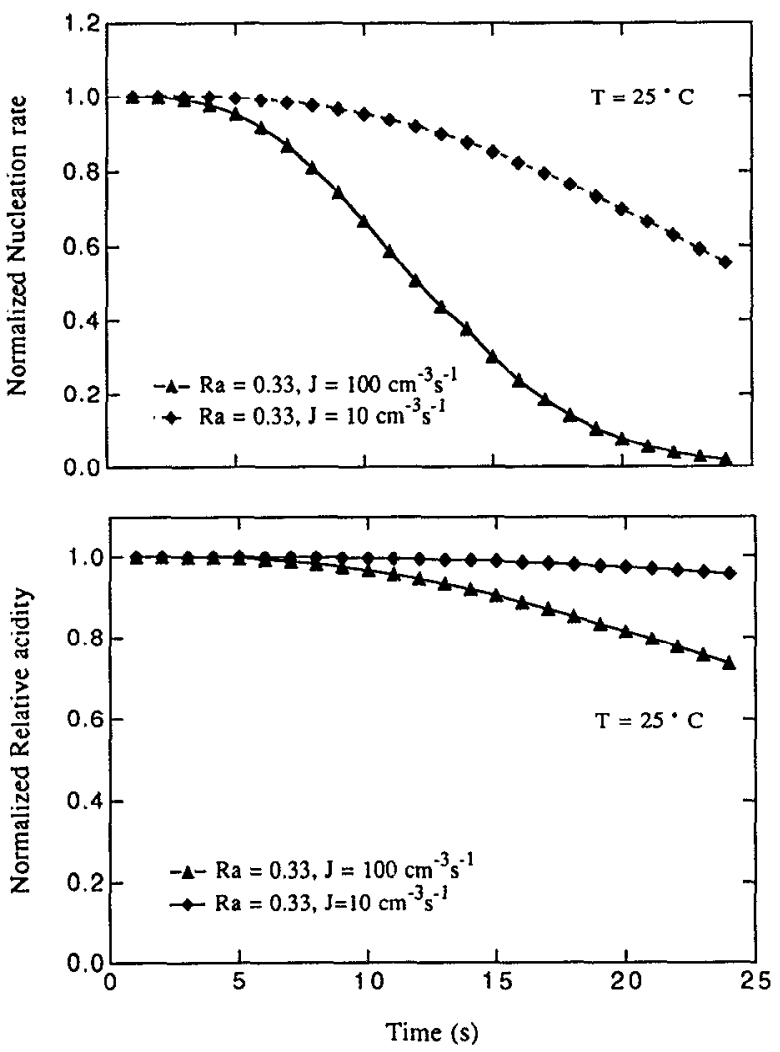

FIG. 18. Simulated profiles along the nucleation path for the MSA-water experiments showing the predicted changes in the normalized nucleation rate and the normalized relative acidity for $J^{0}=100$ and $10 \mathrm{~cm}^{-3} \mathrm{~s}^{-1}$.

of $J^{0}$ show even less acid vapor depletion, and thus the assumption of constant nucleation rates appears to be valid for $J^{0}<10 \mathrm{~cm}^{-3} \mathrm{~s}^{-1}$.

At $J^{0}=100 \mathrm{~cm}^{-3} \mathrm{~s}^{-1}$, the nucleation rate is only $10 \%$ of the initial rate after $t=18 \mathrm{~s}$, corresponding to a $20 \%$ decrease in the initial acid saturation. This means that the points corresponding to $J=100 \mathrm{~cm}^{-3} \mathrm{~s}^{-1}$ in Figs. 7-9, must be reinterpreted slightly to reflect the fact that these points really represent $J_{\text {avg }}=100 \mathrm{~cm}^{-3} \mathrm{~s}^{-1}$. At the indicated saturation levels therefore, the initial rate $J^{0}$ must be somewhat higher than $100 \mathrm{~cm}^{-3} \mathrm{~s}^{-1}$ in order to compensate for reduced nucleation further along the tube.

The particle size results generated by the model using the appropriate correction factor for each temperature were then examined to see if there was qualitative agreement with the size data collected. To make the comparison easier, the mass average particle diameter predicted by the model was multiplied by the polydispersity factor, $\alpha_{p}=0.6$, to give an estimate of the number average particle diameter.

Figure 19 illustrates the predicted and observed variation in the particle diameter as a function of $\mathrm{Rh}$ for the three levels of Ra at $T=30^{\circ} \mathrm{C}$, and the corresponding experimental results. The major trends are clearly followed. The decrease in particle diameter predicted with an increase in $\mathrm{Rh}$ is apparent for the $\mathrm{Ra}=0.33$ and $\mathrm{Ra}=0.15$ experimental data points, although the predicted variations are much larger than those observed. However the predicted variation at $\mathrm{Ra}=0.075$ over the change in $\mathrm{Rh}$ from 0.46 to 0.66 is a factor of three, while the data show no change. Figure 20,
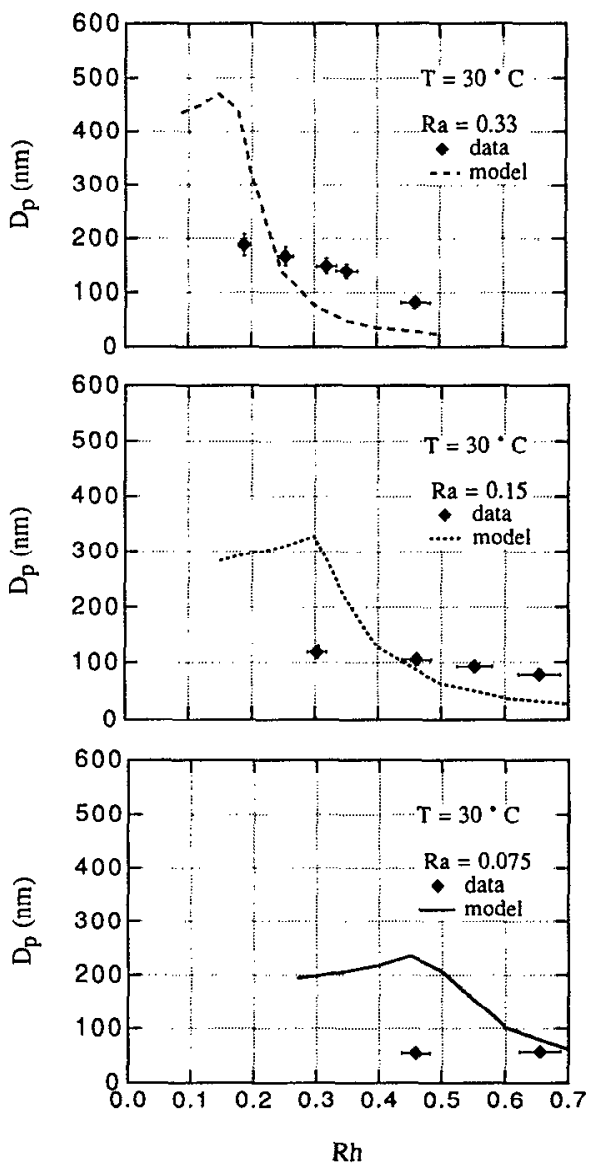

FIG. 19. The predicted particle size at the end of $18 \mathrm{~s}$ of simulation is compared to the observed peak diameter in the number distributions at $T=30^{\circ} \mathrm{C}$. Simulations used the values $\alpha_{p}=0.6, \alpha_{s}=1.0$, and $\mathrm{CF}=10^{-4}$.

again for $T=30^{\circ} \mathrm{C}$, illustrates the corresponding variation of the particle diameter with $\mathrm{Ra}$ for two levels of $\mathrm{Rh}$. The same features are apparent in the previously presented Fig. 13, albeit for different values of $\mathrm{Rh}$.

The current version of the model does not predict the

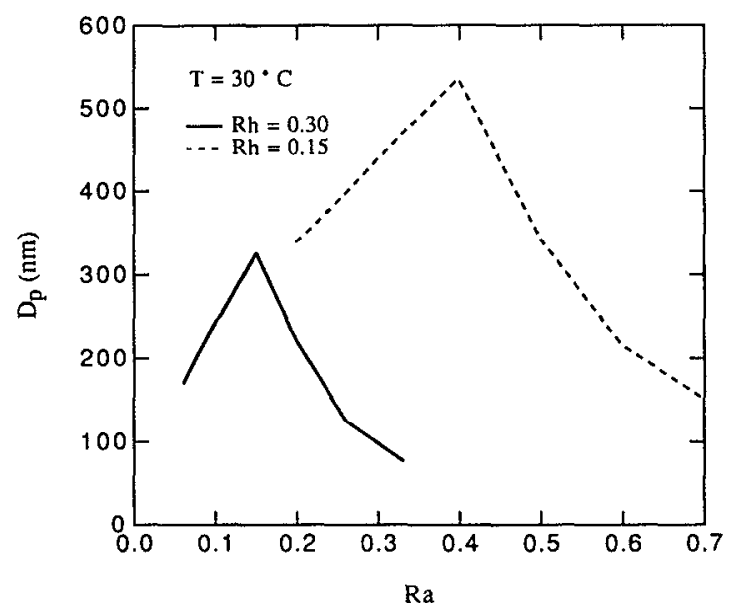

FIG. 20. The predicted variation in the particle diameter with changes in $\mathbf{R a}$ for two levels of $\mathrm{Rh}$. The particles formed at higher relative humidity are predicted to be smaller. This figure should be compared with the data in Fig. 13. 
actual particle sizes very well, although it does confirm that the variations observed are consistent with predictions made using classical nucleation theory and a simple condensation calculation. The incorporation of a sticking probability $\alpha_{s}<1.0$ could improve the agreement with observations by reducing both the maximum particle size predicted and the maximum predicted range $\left(D_{p \max } / D_{p \min }\right)$. However at this point the introduction of a second adjustable parameter is not warranted. A more detailed aerosol model that is capable of predicting size distributions is required and would add more insight to the competing processes of nucleation and condensation.

\section{A. Comparison with previous work}

The only previous experimental work on the MSA-water system is that of Kreidenweis et al. ${ }^{8}$ Conditions in those experiments were somewhat different than in the experiments completed here, but it should be possible to compare results by simulating the data using the experimental nucleation rate correction factor found for the current work at $T=25^{\circ} \mathrm{C}$ and a polydispersity factor of 0.6 . As was the case here, including a correction factor to reduce the nucleation rate greatly improved the agreement between experiments and data. With a correction factor of $10^{-6}$, good agreement was achieved for the $\mathrm{Ra}=0.39$ and 0.34 data. Most of the remaining data were still overestimated by about two orders of magnitude and it appears that a correction factor of about $10^{-8}$ would give the best overall fit of these data.

\section{B. Vapor and particle losses in the experimental system, impact on modeling}

Terms to account for the loss of vapor and particles in the experimental system have not been included in the model. To estimate the particle loss, flow through the tube was modeled as a Graetz problem using the solution given by Brown. ${ }^{35}$ The smallest particles will be on the order of the critical cluster, $\sim 2 \mathrm{~nm}$, and for these $C_{\mathrm{avg}} / C_{0}$ was reduced by $30 \%$ by the tube exit, which does not represent a significant change in the total particle concentration observed.

The vapor loss term is more critical than the particle loss term because of the strong dependence of the nucleation rate on the saturation level. The solution to the Graetz problem assumes that the walls act as perfect sinks and therefore severely overestimates the vapor loss that will occur. There was no visible condensation in any of the experiments even after 7 days of continuous flow through the nucleation tube. In addition, the good repeatability of experiments performed as much as 3 days apart, argues that after the initial conditioning period, vapor losses to the walls are not significantly influencing the nucleation rates.

\section{SUMMARY AND CONCLUSIONS}

Number concentrations of particles produced by binary nucleation between MSA and water were measured over a wide range of $\mathrm{Ra}<1$ and $\mathrm{Rh}<1$, and at three different temperatures. From these data, nucleation rates $J_{\text {exp }}$ were estimated as a function of $\mathrm{Ra}, \mathrm{Rh}$, and $T$. As in the case of homogeneous nucleation, binary nuclcation rates were found to increase with an increase in temperature. This represents the first systematic study of the effect of temperature on binary nucleation rates.

Comparison with $J_{\text {theor }}$, calculated using the classical binary nucleation theory and accounting for the presence of hydrates, shows that $J_{\text {theor }}$ does not agree with $J_{\text {expr }}$ by up to 8 orders of magnitude and that a temperature dependent correction factor is required. Including the effect of hydrates in the rate calculation reduces the disagreement between theory and experiment but does not eliminate it. Once the correction factor is incorporated into the model for nucleation and growth, the original number concentration data are reasonably well described. The change in the correction factor with temperature, from $10^{-8}$ at $19^{\circ} \mathrm{C}$ to $10^{-4}$ at $30^{\circ} \mathrm{C}$, is opposite to that found by others ${ }^{7,30,31}$ for homomolecular, homogeneous nucleation.

The observed particle size distributions varied with changes in $\mathrm{Ra}$ and $\mathrm{Rh}$ in a manner that was consistent with a simple model of nucleation and growth. The competition between the two processes was clearly illustrated in Fig. 13, where increases in $\mathrm{Ra}$ first increase the average particle size (condensation dominates), and then decrease the average particle size (nucleation dominates). A more sophisticated aerosol model is required to better predict the experimental particle size data.

The continuous flow mixing apparatus provides an excellent tool for studying binary nucleation processes at saturation levels less than one, and seems to be the best way to work with such corrosive and difficult systems as acid and water.

\section{ACKNOWLEDGMENTS}

The authors gratefully acknowledge the assistance of Sonia Kreidenweis who provided computer programs used to correlate the physical property data and simulate the experiments. This work was supported by National Science Foundation Grant No. ATM-9003186 and by the Alberta Heritage Scholarship Fund (B.E.W.).

'G. J. Doyle, J. Chem. Phys. 35, 795 (1961).

${ }^{2}$ H. J. Rciss, J. Chem. Phys. 18, 840 (1950).

${ }^{3}$ H. Reiss, D. I. Margolese, and F. J. Schelling, J. Colloid Interface Sci. 56, $S 11$ (1976).

${ }^{4}$ F. J. Schelling and H. Reiss, J. Colloid Interface Sci. 83, 246 (1981).

${ }^{5}$ D. Boulaud, G. Madelaine, D. Vilga, and J. Bricard, J. Chem. Phys. 66, 4854 (1977).

${ }^{6}$ P. Mirabel and J. L. Clavelin, J. Chem. Phys. 68, 5020 (1978).

${ }^{7}$ C. H. Hung, M. J. Krasnopoler, and J. L. Katz, J. Chem. Phys. 90, 1856 (1989).

${ }^{8}$ S. Kreidenweis, R. Flagan, J. Seinfeld, and K. Okuyama, J. Aer. Sci. 20, 585 (1989).

${ }^{9}$ R. J. Charlson, J. E. Lovelock, M. O. Andreae, and S. G. Warren, Nature 326, 655 (1987).

${ }^{10}$ S. E. Schwartz, Nature 336, 441 (1988).

${ }^{11}$ K. Okuyama, Y. Kousaka, S. Kreidenweis, R. C. Flagan, and J. H. Seinfeld, J. Chem. Phys. 89, 6442 (1988).

${ }^{12}$ S. C. Wang, and R. C. Flagan, Aerosol Sci. Technol. 13, 230 (1990).

${ }^{13}$ See AIP document no. PAPS JCPSA-94-6827-15 for 15 pages of Order by PAPS number and journal reference from American Institute of Physics, Physics Auxiliary Publication Service, 335 East 45th Street, New York, NY 10017. The price is $\$ 1.50$ for each microfiche (98 pages) or $\$ 5.00$ for photocopies of up to 30 pages, and $\$ 0.15$ for each additional page over 30 pages. Airmail additional. Make checks payable to the American Institute of Physics. 
${ }^{14}$ D. Stauffer, J. Aer. Sci. 7, 319 (1976).

15. R. G. Reninger, F. C. Hiller, and R. C. Bone, J. Chem. Phys. 75, 1584 (1981).

${ }^{16} \mathrm{G}$. Wilemski, J. Chem. Phys. 80,1370 (1984).

${ }^{17}$ P. Mirabel, and H. Reiss, Langmuir 3, 228 (1986),

${ }^{1 *}$ R. H. Heist and H. Reiss, J. Chem. Phys. 61, 573 (1974).

${ }^{10}$ A. Jaecker-Voirol, P. Mirabel, and H. Reiss, J. Chem. Phys. 87, 4849 (1987).

${ }^{20}$ A. Jaecker-Voirol, P. Mirabel, and H. Reiss, J. Chem. Phys. 88, 3518 (1987).

21 P. Mirabel (personal communication) (1990).

${ }^{22}$ B. Dahneke, in Theory of Dispersed Multiphase Flow, edited by R. E. Meyer (Academic, New York, 1983), p. 97.

${ }^{23}$ R. Van Dingenen, PhD thesis, State University Ghent (1990).

${ }^{24}$ R. C. Reid, J. M. Prausnitz, and B. E. Poling, The Properties of Gases and Liquids (McGraw-Hill, New York, 1987).
${ }^{25}$ J. H. Seinfeld, The Atmospheric Chemistry and Physics of Air Pollution (Wiley, New York, 1986).

${ }^{26}$ I. N. Tang (personal communication) (1990).

${ }^{27}$ T. T. Teng and F. Lenzi, J. Chem. Eng. Data 20, 432 (1975).

${ }^{28}$ I. N. Tang and H. R. Munkelwitz, J. Colloid Interface Sci. 141, 109 (1991).

${ }^{29}$ W. F. Giauque, E. W. Hornung, J. E. Kunzler, and T. R. Rubin, J. Am. Chem. Soc. 82, 62 (1960).

${ }^{30}$ R. Strey, P. E. Wagner, and T. Schmeling, J. Chem. Phys. 84, 2325 (1986).

${ }^{31}$ P. E. Wagner and R. Strey, J. Chem. Phys. 80, 5266 (1984).

${ }^{32}$ G. W. Adams, J. L. Schmitt, and R. A. Zalabsky, J. Chem. Phys. 81, 5074 (1984).

${ }^{33}$ C. Flageollet, M. D. Cao, and P. Mirabel, J. Chem. Phys. 72, 544 ( 1980 ).

${ }^{34}$ J. P. Garnier and P. Mirabel, J. Chem. Phys. 77, 2035 (1982).

${ }^{35}$ G. M. Brown, AIChE J. 6, 179 (1960). 